\title{
Temperature stabilization, ocean heat uptake and radiative forcing overshoot profiles
}

\author{
Daniel J. A. Johansson
}

Received: 15 September 2009 / Accepted: 5 October 2010 / Published online: 7 December 2010

(C) The Author(s) 2010. This article is published with open access at Springerlink.com

\begin{abstract}
Political leaders in numerous nations argue for an upper limit of the global average surface temperature of $2 \mathrm{~K}$ above the pre-industrial level, in order to attempt to avoid the most serious impacts of climate change. This paper analyzes what this limit implies in terms of radiative forcing, emissions pathways and abatement costs, for a range of assumptions on rate of ocean heat uptake and climate sensitivity. The primary aim is to analyze the importance of ocean heat uptake for radiative forcing pathways that temporarily overshoot the long-run stabilization forcing, yet keep the temperature increase at or below the $2 \mathrm{~K}$ limit. In order to generate such pathways, an integrated climate-economy model, MiMiC, is used, in which the emissions pathways generated represent the least-cost solution of stabilizing the global average surface temperature at $2 \mathrm{~K}$ above the pre-industrial level. We find that the level of overshoot can be substantial. For example, the level of overshoot in radiative forcing in 2100 ranges from about 0.2 to $1 \mathrm{~W} / \mathrm{m}^{2}$, where the value depends strongly and positively on the effective diffusivity of heat in the oceans. Measured in relative terms, the level of radiative forcing overshoot above its longrun equilibrium level in 2100 is $20 \%$ to $60 \%$ for high values of climate sensitivity (i.e., about $4.5 \mathrm{~K}$ ) and $8 \%$ to $30 \%$ for low values of climate sensitivity (i.e., about $2 \mathrm{~K}$ ). In addition, for cases in which the radiative forcing level can be directly stabilized at the equilibrium level associated with a specific climate sensitivity and the $2 \mathrm{~K}$ limit, the net present value abatement cost is roughly cut by half if overshoot pathways are considered instead of stabilization of radiative forcing at the equilibrium level without an overshoot.
\end{abstract}

\section{J. A. Johansson $(\bowtie)$}

Division of Physical Resource Theory, Department of Energy and Environment,

Chalmers University of Technology, Gothenburg, Sweden

e-mail: daniel.johansson@chalmers.se

D. J. A. Johansson

Environmental Economics Unit, Department of Economics,

School of Business, Economics and Law,

Gothenburg University, Gothenburg, Sweden 


\section{Introduction}

The objective of the United Nations Framework Convention (UFNCCC), stated in Article 2, is to stabilize the concentration of greenhouse gases in the atmosphere at a level "that would prevent dangerous anthropogenic interference with the climate system". Numerous papers address how to transform this value-laden objective into more hands-on climate targets; see for example Azar and Rodhe (1997), O'Neill and Oppenheimer (2002), Oppenheimer and Petsonk (2005) and Harvey (2007a, b). A common starting point for the discussion of what constitutes dangerous anthropogenic interference is that the global average surface temperature should be kept below a certain level above the pre-industrial level; see Azar and Rodhe (1997), O’Neill and Oppenheimer (2002) for examples. Given the large uncertainties in climate sensitivity, it is overly hard to judge which atmospheric concentrations and greenhouse gas emissions pathways are consistent with a specific temperature target.

Recent papers have argued that, for a finite period of time, radiative forcing could overshoot the long-term equilibrium level consistent with a temperature limit and a given climate sensitivity; see den Elzen and van Vuuren (2007), Harvey (2007b) and Matthews and Caldeira (2008). Such overshoots are possible due to the inertia of the climate system; see den Elzen and van Vuuren (2007) and Wigley (2004). This inertia is mainly a result of the large heat uptake by the oceans (Hansen et al. 1985, 2005; Harvey and Schneider 1985; Stouffer 2004; Wigley and Schlesinger 1985; Meehl et al. 2005; Wigley 2005).

den Elzen and van Vuuren (2007), Harvey (2007b) and Matthews and Caldeira (2008) analyze the importance of climate inertia for temperature stabilization scenarios. den Elzen and van Vuuren (2007) argue that, given a target below or at which the increase in global average surface temperature above the pre-industrial level is to be kept, it is cost-effective to let the radiative forcing overshoot its long-run equilibrium level. Hence, in their analysis, climate inertia implies that emission reductions can, in part, be postponed; the Net Present Value (NPV) costs are reduced when overshoot pathways are considered, since future costs are discounted. Harvey (2007b) argue that the peak realized warming will be less than the peak equilibrium warming related to the peak radiative forcing and that this allows the $\mathrm{CO}_{2}$ concentration to overshoot the long run equilibrium level needed to avoid dangerous anthropogenic interference by 10-40 ppm in 2100. Matthews and Caldeira (2008) argue that a stable global temperature is not necessarily equivalent to a stable radiative forcing level; instead, a stable temperature may have an overshoot in forcing that subsequently decreases. They also argue that a stable temperature in the long run requires that $\mathrm{CO}_{2}$ emissions must decrease to (nearly) zero.

Baker and Roe (2009) argue that ocean heat uptake can be seen as a transient negative climate feedback. In addition, by using an Energy Balance Model (EBM) and Monte Carlo analysis, they analyze the relative importance of climate sensitivity versus ocean heat uptake for the evolution of the global average surface temperature response to a set of radiative forcing profiles. They conclude that climate sensitivity is more important than ocean heat uptake for determining the temperature response of a forcing profile.

Allen et al. (2009) argue for cumulative $\mathrm{CO}_{2}$ emissions targets instead of concentration (or radiative forcing) stabilization targets. Their arguments are related to arguments for overshoot scenarios and they reason that the temperature response 
of cumulative emissions targets is better constrained than that of concentration stabilization targets. They also argue that cumulative emissions targets are less complicated from a policy perspective than overshoot targets. On the other hand, cumulative emissions targets may not be suitable for short-lived greenhouse agents such as methane and black carbon.

Overshoot scenarios have also been analyzed in O'Neill and Oppenheimer (2004) and Schneider and Mastrandrea (2005). These papers conclude that for a given radiative forcing stabilization level, overshoot scenarios enhance the risk of dangerous anthropogenic interference. Note that O'Neill and Oppenheimer (2004) also argue that overshoot scenarios may imply a higher rate of temperature change which in turn may have negative consequences.

No study has yet analyzed how different rates of ocean heat uptake influence the tolerable level of radiative forcing overshoot given stabilization of the global average surface temperature at a specific level. This study seeks to do so. We analyze how different levels of effective heat diffusivity influence the level of radiative forcing overshoot, given a stabilization of the global mean surface temperature at $2 \mathrm{~K}$ above the pre-industrial level at lowest possible cost in net present value terms. A reasonable hypothesis in conjunction with this issue is that the level of cost-effective radiative forcing overshoot increases with increasing effective heat diffusivity. The question is, by how much?

In this study, climate inertia is limited to the inertia caused by the heat uptake of the oceans. The oceans account for roughly $90 \%$ of the energy uptake by the climate system between 1961 and 2003 (Bindoff et al. 2007). The analysis is carried out by using an optimizing climate-economy model, MiMiC, and systematic sensitivity analyses (Monte Carlo analyses) concerning the effective heat diffusivity and climate sensitivity. In this paper we do not take a risk-based approach, as, for example, Allen et al. (2009) and Meinshausen et al. (2009) do, rather, our aim is to analyze the level of overshoot given different assumptions on climate sensitivity and effective heat diffusivity.

The $2 \mathrm{~K}$ limit is not a scientific target, but a political target involving value judgments, but it is also well-accepted among many scientists (Allan et al. 2007; Azar and Rodhe 1997; Oppenheimer and Petsonk 2005) and has recently been given support by the G8, G20 and Major Economics Forum countries. Currently, countries that constitute a majority of the world's population have expressed support for a $2 \mathrm{~K}$ target, manifested, for example, by the Copenhagen Accord. ${ }^{1}$ However, given all the uncertainties in the climate system, this limit should be interpreted as an indication rather than a strict level on what global mean surface temperature increase may be considered dangerous. Serious climate impacts may occur below a $2 \mathrm{~K}$ level; see for example O'Neill and Oppenheimer (2002), Lenton et al. (2008) and Smith et al. (2009).

Section 2 presents the numerical model, Section 3 presents the results, and we conclude and discuss in Section 4.

${ }^{1}$ The Copenhagen Accord does not actually specify relative to what benchmark the "increase in global temperature should be below 2 degrees Celsius." 


\section{Methodology}

In order to generate plausible multigas emissions stabilization scenarios assuming a range of values for the effective heat diffusivity and climate sensitivity, we use a timediscrete climate-economy model. Emissions of carbon dioxide, methane and nitrous oxide are determined endogenously in the model so as to minimize the net present value abatement cost of stabilizing the global average surface temperature at $2 \mathrm{~K}$ above the pre-industrial level. The trade-offs among the different greenhouse gases are not constrained by their Global Warming Potentials (GWPs); the abatement of the emissions of each gas is determined to achieve the lowest cost of temperature stabilization; see Manne and Richels (2001) and Johansson et al. (2006).

The numerical model is an updated version of the MiMiC model presented and used in Johansson et al. (2006, 2008). The main differences between the model used here and the versions in Johansson et al. (2006, 2008) are that the energy balance model has been improved (by the use of a three-box energy balance model that is calibrated to an upwelling-diffusion energy balance model), the carbon cycle representation has been recalibrated, climate-feedbacks in the carbon cycle are taken into account, and updated data have been used to initialize and fit the model to the historical global average radiative forcing and surface temperature levels. In this paper we discuss the major changes in the model that have been made for the specific purpose of the study and refer to Johansson et al. (2006) for a general presentation.

The model runs between 1880 and 2600 with annual time steps over the period 1880 to 2004 and 5-year time-steps over the period 2005 to 2600 . The period 1880 to 2004 is used to calibrate the forcing strength of aerosols (both direct and indirect effects) and to initialize the carbon cycle and energy balance model.

\subsection{Scenario and economic module}

Baseline emissions for the well-mixed greenhouse gases $\mathrm{CO}_{2}, \mathrm{CH}_{4}$, and $\mathrm{N}_{2} \mathrm{O}$ for the period 2015-2100 are taken from the IIASA A2r scenario, which is an updated version of the SRES A2; see Riahi et al. (2006) and IIASA (2009). The A2r scenario can be characterized as a scenario with high population growth, low per capita economic growth and reliance on fossil fuel technologies. After 2100 the baseline emissions are assumed to remain constant and eventually decline due to a constraint that the cumulative carbon emissions from fossil sources cannot exceed $5000 \mathrm{Gton} \mathrm{C}$ due to limitations on extractable fossil fuel resources. However, this constraint will never be binding in the stabilization scenarios studied in this paper; the cumulative carbon emissions are considerably less than 5000 Gton C. $\mathrm{CO}_{2}$ emissions from land use change follow the A2r baseline scenario.

The economic module is simple and gives only rough indications on the costs of reducing emissions of greenhouse gases. The main use of the economic model in this paper is to generate plausible stabilization scenarios. Abatement of emissions is only allowed from the year 2015 and onwards. The costs of abatement are modeled by use of abatement cost functions, see Eqs. 1, 2 and 3, Table 1 and Johansson et al. (2006) for details on these functions. For the sake of simplicity the abatement cost functions are assumed to be constant over time. The level of abatement $a_{\mathrm{CO} ;} ; a_{\mathrm{N} 2 \mathrm{O}}$ and $a_{C H 4}$ is abatement of each gas in relative terms compared to the baseline 
Table 1 Constants used in the marginal abatement cost functions given in Eqs. 1, 2 and 3

\begin{tabular}{llcr}
\hline & $\mathrm{CO}_{2}$ & $\mathrm{CH}_{4}$ & $\mathrm{~N}_{2} \mathrm{O}$ \\
\hline$\alpha$ & 0.79 & 34.3 & 127 \\
$\beta$ & 0.092 & 0.10 & 0.16 \\
\hline
\end{tabular}

The marginal cost are calculated in US $\$_{2000}$ per ton emission, i.e. per ton $\mathrm{C}, \mathrm{CH}_{4}$ and $\mathrm{N}_{2} \mathrm{O}$, respectively

emissions (percent of baseline) and $M C_{C O 2}, M C_{N 2 O}$ and $M C_{C H 4}$ is the marginal cost of abatement.

$$
\begin{gathered}
M C_{\mathrm{CO}_{2}}=\alpha_{\mathrm{CO}_{2}} \cdot a_{\mathrm{CO}_{2}}+\beta_{\mathrm{CO}_{2}} \cdot a_{C O_{2}}^{2} \\
M C_{\mathrm{CH}_{4}}=\alpha_{\mathrm{CH}_{4}} \cdot\left(e^{\beta_{\mathrm{CH}_{4}} \cdot a_{\mathrm{CH}_{4}}}-1\right) \\
M C_{\mathrm{N}_{2} \mathrm{O}}=\alpha_{\mathrm{N}_{2} \mathrm{O}} \cdot\left(e^{\beta_{N_{2} O} \mathrm{O} \cdot a_{N_{2} O}}-1\right)
\end{gathered}
$$

Constraints on how fast emissions can be reduced are implemented in the model. The ratio of actual emissions to baseline emissions can decline at a maximum of 4 percentage points per year. In addition, there is a constraint that implies that it takes at least 10 years to reach this maximum level of the rate of relative abatement decline. These constraints are very weak. In practice they imply that the emissions of $\mathrm{CO}_{2}$ (from fossil sources), $\mathrm{CH}_{4}$, and $\mathrm{N}_{2} \mathrm{O}$ can be reduced to zero by year 2045 (although at a very high cost). The reason for having such weak constraints is that we want to have as many feasible solutions in the optimization as possible, yet exclude the most unrealistic emissions pathways.

The radiative forcing for halocarbons and aerosols is assumed to decline over time. For halocarbons, the radiative forcing declines at $1 \%$ per year. This decline rate corresponds to the inverse of the atmospheric lifetime of the radiatively most important CFC, i.e., CFC-12. Note that most other halocarbons making a nonnegligible contribution to radiative forcing have shorter life-times than this. For HFC's there is a low-cost abatement potential, see USEPA (2006). However, if these gases are not targeted by policies, their contribution to radiative forcing could become large; see Velders et al. (2009). For aerosols, the radiative impact is constant at the 2000 level up to 2015 and then declines at $3 \%$ per year. This is a reasonable scenario for the aerosol forcing given the strong interdependence with fossil $\mathrm{CO}_{2}$ emissions (which decline in the model in order to meet the temperature target).

Choosing a discount rate to deflate future abatement cost is contentious. Basically, there are two main approaches to choosing a long-term discount rate: either a prescriptive approach based on ethics and assumptions regarding future growth in consumption (Dasgupta 2008), or a descriptive approach based on assumptions regarding future returns to capital (Nordhaus 2008). In this model we use a discount rate of $4 \%$ per year and do not delve into this controversial issue. To deal with the problems of choosing a long-term discount rate, the model is also analyzed with two alternative discount rates, $2 \%$ and $6 \%$ per year, respectively. The low rate is slightly 
higher than the rates used by for example Stern (2006) and the high rate is in line with the rates used by for example Nordhaus (2008).

\subsection{Energy balance model}

The energy balance model used to calculate the temperature response within the optimization is a globally averaged box model with three boxes. This three-box model consists of a mixed ocean-atmosphere layer, an intermediate ocean layer and a deep ocean layer. This model is calibrated to emulate a linear Upwelling Diffusion Energy Balance Model (UDEBM) with polar overturning; see Appendices 1 and 2. The equivalent heat capacities of the boxes and the transfer coefficient between them are, in the three box model, set to imitate the surface temperature response of the UDEBM; see Appendix 2.

The reason for using a calibrated three-box EBM instead of the UDEBM within the optimization algorithm is to speed up the model solution time and to avoid problems with numerical instability. The error generated by the use of the three-box EBM instead of the UDEBM is insignificant; see Appendix 2.

The base case assumptions include a climate sensitivity (CS) of $3 \mathrm{~K}$ for a doubling of the atmospheric $\mathrm{CO}_{2}$ concentration, an upwelling rate of $4 \mathrm{~m} /$ year and a ratio of polar water warming to average ocean warming of 0.2 ; see Appendix 1 for more details and additional assumptions. An upwelling of $4 \mathrm{~m} / \mathrm{yr}$ corresponds to a downwelling/upwelling of water into the deep oceans of about $45 \mathrm{~Sv}$ (1 Sv= $10^{6} \mathrm{~m}^{3} / \mathrm{s}$ ). This value is higher, in general, than downwelling estimates based on observations presented in Harvey (1996), Munk and Wunsch (1998), and Whitworth et al. (1999), but in line with upwelling estimates presented in Whitworth et al. (1999), and a standard assumption in many other UDEBM, see for example Munk (1966), Hoffert et al. (1980), Harvey and Huang (2001), Wigley and Raper (2001), Lowe et al. (2009), and Meinshausen et al. (2009). In order to analyze different rates of ocean heat uptake, different values for the effective heat diffusivity is assumed. This is the most common way of representing different rates of ocean heat uptake in UDEBMs; see Raper et al. (2001), Wigley and Raper (2001), Lowe et al. (2009), and Meinshausen et al. (2009). For the effective heat diffusivity we test for three values, $0.5,1.5$ and $3 \mathrm{~cm}^{2} / \mathrm{s}$. The rationales for choosing these values are:

1. An effective diffusivity of 0.5 to $1 \mathrm{~cm}^{2} / \mathrm{s}$ is required to give a good fit between the global average depth dependent temperature profile of the oceans as reported by Levitus (1982) and simple UDEBMs with similar structure and parameterization as the model used in this paper, see e.g. Hoffert et al. (1980), Harvey and Huang (2001) and Raper et al. (2001). This has also been tested and confirmed with the model used in this study. Accordingly, we set the low value of the effective diffusivity to $0.5 \mathrm{~cm}^{2} / \mathrm{s}$.

2. To mimic the transient surface temperature change and the change in the global average depth-dependent temperature profile of the oceans that are generated in AOGCMS when the radiative forcing is changed, higher diffusivities are often needed than those reported in bullet 1 above; see Raper et al. (2001). For this reason we also set the effective diffusivity to 1.5 and $3 \mathrm{~cm}^{2} / \mathrm{s}$ as our medium and high values, respectively; see also Meinshausen et al. (2008) concerning calibration of the effective diffusivity. 
2.3 Carbon cycle and other greenhouse gases

To model the sink of atmospheric $\mathrm{CO}_{2}$, linear impulse response functions based on Joos et al. (1996) and Tanaka (2008) are used; see Appendix 3 for details. For the forward looking modeling, the impulse response function is linearized around an atmospheric $\mathrm{CO}_{2}$ concentration of $450 \mathrm{ppm}$, while for the initialization of our carbon cycle model the impulse response is linearized around an atmospheric $\mathrm{CO}_{2}$ concentration of $325 \mathrm{ppm}$. Given the limited non-linearities in the carbon cycle for atmospheric levels below a doubling of the pre-industrial level (Hooss et al. 2001), the linearization procedure used here gives only small deviations from results obtained using the non-linear carbon cycle representation. Further, the climatecarbon cycle feedbacks are also taken into account based on results in Matthews (2006), Plattner et al. (2008), Thorn and Harte (2006) and Frank et al. (2010); see Appendix 3 for details.

$\mathrm{CH}_{4}$ and $\mathrm{N}_{2} \mathrm{O}$ concentrations are modeled using the global mean mass-balance equations in Prather et al. (2001), taking the feedback effect $\mathrm{CH}_{4}$ has on its own atmospheric lifetime into account. The equations for radiative forcing are the expressions given in Ramaswamy et al. (2001). We also include the indirect effect of methane on tropospheric ozone and stratospheric water vapor (Wigley et al. 2002).

\subsection{Calibration}

The global average surface temperature and the heat uptake in the three-box energy balance model are initiated and calibrated so as to fit the historical temperature by adjusting the radiative forcing contribution from aerosols (the sum of direct and indirect radiative forcing from both reflecting and absorbing aerosols) given different exogenously set values for the climate sensitivity and effective heat diffusivity. In the calibration, the strength of the aerosol forcing is determined by minimization of the least square difference between the modeled global average surface temperature and the measured historical global average surface temperature. This is a simple approach of determining the radiative forcing strength of aerosols, and it serves to make the historic simulation and the scenario consistent for a large range of assumptions on the effective heat diffusivity and climate sensitivity.

For the calibration of net aerosol forcing and initialization of the energy balance model, the historical radiative forcing contributions from $\mathrm{CO}_{2}, \mathrm{CH}_{4}$ (both direct and indirect effects), $\mathrm{N}_{2} \mathrm{O}$, Halocarbons, changes in solar activity, and the radiative impacts of volcanoes are considered. The historical forcing contributions from $\mathrm{CO}_{2}$, $\mathrm{CH}_{4}, \mathrm{~N}_{2} \mathrm{O}$ are calculated by using the approach described in Section 2.3 together with historical atmospheric concentrations presented in NASA GISS (2009a). The radiative forcing contributions from Halocarbons, changes in solar activity, and volcanoes are from NASA GISS (2009a). Data on the global average surface temperature are from NASA GISS (2009b). Other forcing changes since pre-industrial times, such as non- $\mathrm{CH}_{4}$-induced tropospheric $\mathrm{O}_{3}$ leading to an increase in radiative forcing, and changes in surface albedo leading to a net decrease in radiative forcing, are assumed to balance; see Forster et al. (2007).

The model is run as follows:

1. Set the climate sensitivity and the effective heat diffusivity.

2. Calibrate the three-box EBM to the UDBM for a step forcing of $4 \mathrm{~W} / \mathrm{m}^{2}$. 
3. Initiate the carbon cycle model with historic $\mathrm{CO}_{2}$ emissions from CDIAC (2010).

4. Calibrate the radiative strength of the net aerosol forcing so as to minimize the squared difference between modeled global average surface temperature and measured historical global average surface temperature. The ocean heat content is calculated in the calibration procedure.

5. Run the forward looking optimization model to determine cost-effective emissions pathways leading to a stabilization of the global average surface temperature at $2 \mathrm{~K}$ above the pre-industrial level.

\subsection{Uncertainty analysis}

In order to corroborate the results we performed a range of sensitivity tests. We test the model specifically to two parameters in the economic module, the discount rate and the baseline emissions scenario, respectively; see Section 3.4 for details. In addition, we perform a Monte Carlo Analysis where random numbers for the climate sensitivity and the effective heat diffusivity are drawn.

Obviously, other assumptions in the model, such as the carbon cycle specification and rate of upwelling, are also important for the overall results and are uncertain. However, since the main aim is to study the combined importance of effective heat diffusivity and climate sensitivity for pathways resulting in stabilization of global average surface temperature, the Monte Carlo analyses are limited to these two parameters.

The probability distribution for the climate sensitivity is assumed to be log-normal with the 17 th percentile being equal to $2 \mathrm{~K}$ and the $83 \mathrm{rd}$ percentile being equal to $4.5 \mathrm{~K}$. This corresponds to a cautious interpretation of the likely span for the climate sensitivity as presented in Meehl et al. (2007). Also, with the long upper tail generated by the log-normal distribution the problem of constraining the climate sensitivity upward is taken into account, see Hegerl et al. (2007), Randall et al. (2007), Roe and Baker (2007) and Knutti and Hegerl (2008). In addition, climate sensitivity is limited upward to $10 \mathrm{~K}$. In practice, this has no effect on the model results since the optimization model will never find any feasible solution for climate sensitivities above about $5 \mathrm{~K}$. For the effective heat diffusivity, the 17 th and 83 rd percentile are set to 0.5 and $3.0 \mathrm{~cm}^{2} / \mathrm{s}$ and a maximum value of $6 \mathrm{~cm}^{2} / \mathrm{s}$ is assumed. This is in line with the heat diffusivities used in MAGICC when emulating AOGCMS; see Cubasch et al. (2001), Wigley and Raper (2001), Meehl et al. (2007), Meinshausen (2006) and Meinshausen et al. (2008, 2009). As discussed by Forest et al. (2006) and Andrews and Allen (2008), some AOGCMs tend to show a too high heat uptake and consequently a too slow temperature response when compared to historical estimates. Therefore, slightly higher probabilities for low diffusivities are assumed than in for example Wigley and Raper (2001).

The constraints on how fast emissions can drop are removed in the Monte Carlo analysis. This is done to simplify the interpretation of the results concerning the importance of the climate sensitivity and effective heat diffusivity.

As in the main runs, the negative radiative forcing contribution from aerosols is estimated for each set of values for climate sensitivity and effective heat diffusivity by minimization of the squared error of the modeled temperature to the measured temperature for the time period 1880 to 2004.

For illustrative purposes and to show that the model is well-behaved, the relationships between climate sensitivity, effective heat diffusivity, aerosol forcing strength, 


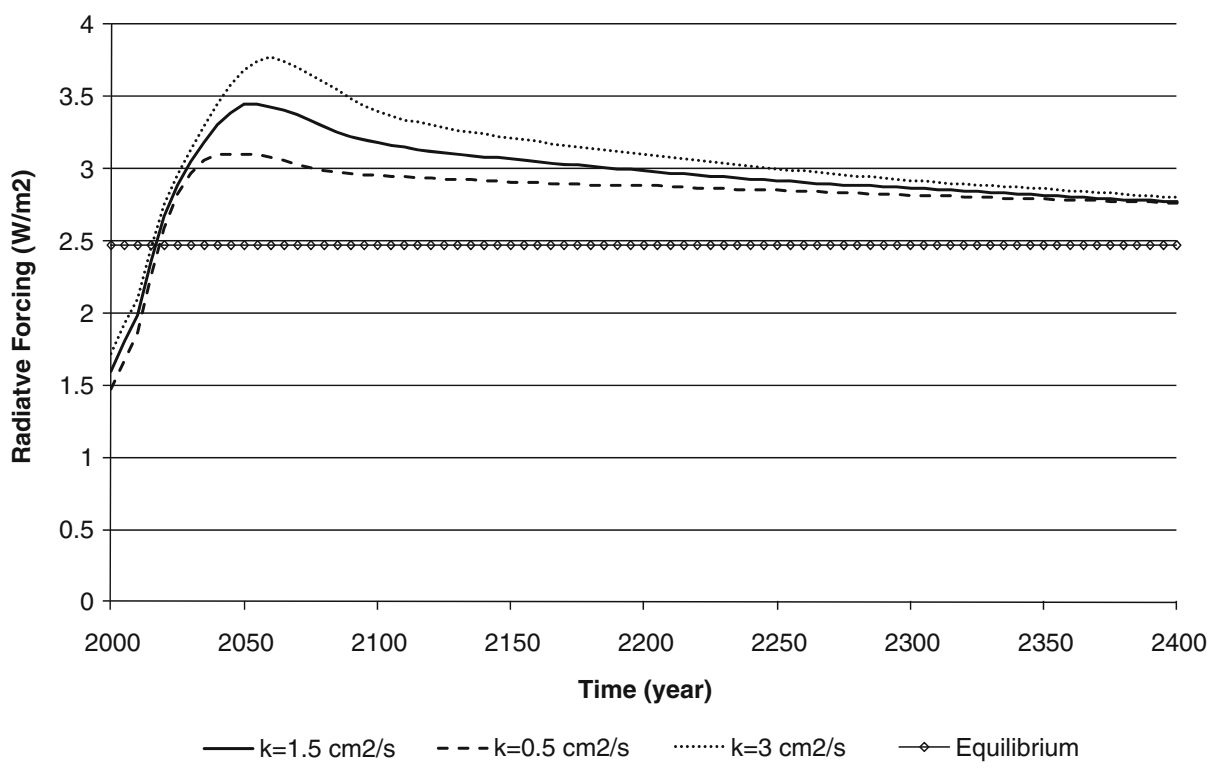

Fig. 1 Radiative forcing pathways (net of greenhouse gases and aerosols) leading to a stabilization of the temperature at $2 \mathrm{~K}$, given a climate sensitivity of $3 \mathrm{~K}$ and no temperature overshoot

and historical heat uptake by oceans are presented and discussed in Appendices 4 and 5 .

\section{Results}

\subsection{Radiative forcing pathways leading to temperature stabilization}

The uptake of heat in the oceans results in the temperature responding slowly to changes in radiative forcing. As a consequence of this heat uptake, the radiative forcing can substantially overshoot the long-run equilibrium level, see Fig. 1. The equilibrium radiative forcing must eventually be reached in order to stabilize the temperature at a certain level, in our case at the $2 \mathrm{~K}$ limit. The equilibrium is reached beyond 2400, while the global average surface temperature is stabilized at $2 \mathrm{~K}$ above the pre-industrial level around 2070-2080; see Fig. 2.

The level of overshoot increases with increasing rate of effective heat diffusivity; see Fig. $1 .^{2}$ This is a result of the transient and total heat uptake being higher, the higher the effective diffusivity; see also Appendix 6. The maximum level of overshoot for the high heat diffusivity $\left(3 \mathrm{~cm}^{2} / \mathrm{s}\right)$ is more than $1 \mathrm{~W} / \mathrm{m}^{2}$ above the longrun equilibrium level $^{3}$ in our base case with a climate sensitivity of $3 \mathrm{~K}$ (see also

\footnotetext{
${ }^{2}$ The effective heat diffusivity is denoted $\mathrm{k}$ in graphs and tables throughout the paper.

${ }^{3}$ For the concentration levels analyzed here, a $1 \mathrm{~W} / \mathrm{m}^{2}$ overshoot roughly corresponds to a $90 \mathrm{ppm}$ $\mathrm{CO}_{2}$-equivalent concentration overshoot.
} 


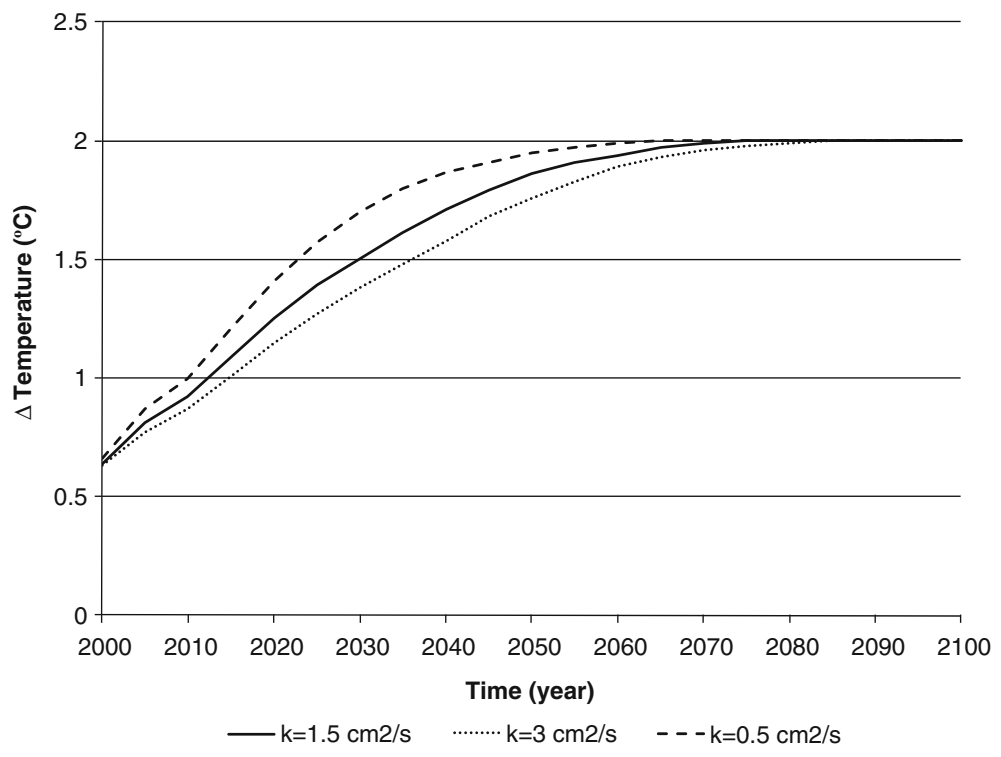

Fig. 2 Temperature profile for different levels of the effective heat diffusivity all leading to a stabilization at $2 \mathrm{~K}$ above the pre-industrial level, given a climate sensitivity of $3 \mathrm{~K}$

Section 3.4.2 for Monte Carlo analysis involving a span of different sensitivities). For the low heat diffusivity $\left(0.5 \mathrm{~cm}^{2} / \mathrm{s}\right)$, the maximum level of overshoot is still slightly above $0.5 \mathrm{~W} / \mathrm{m}^{2}$; see Fig. 1 .

Note also that the temperature during the twenty-first century is higher, the lower the effective diffusivity; see Fig. 2. This result would be expected if the forcing were equal in the three cases, but the forcing is lower, the lower the diffusivity; see Fig. 1.

The three different radiative forcing pathways presented in Fig. 1 converge over time. The long-term overshoot value that the different radiative forcing pathways converges to strongly depends on the relative warming of the downwelling water in polar regions to that of global average sea surface warming; see Hoffert et al. (1980) and Jarvis and Li (2010) for related studies. As seen in Fig. 1, in year 2400, the level of overshoot is still about $0.3 \mathrm{~W} / \mathrm{m}^{2}$ above the equilibrium level and not strongly dependent on the effective heat diffusivity.

\section{2 $\mathrm{CO}_{2}$-equivalent emissions pathways leading to temperature stabilization}

The increased potential for radiative forcing overshoot with increasing levels of effective heat diffusivity implies that more $\mathrm{CO}_{2}$-equivalent emissions (using GWP's calculated over 100 years) can be emitted during the twenty-first century the higher the effective diffusivity; see Fig. 3. The difference in cumulative emissions for the high and low diffusivity case is about $170 \mathrm{GtC}$-equivalents. This is slightly larger than the amount of carbon stored in global oil reserves reported by BP (2009).

The concentration level of greenhouse gases is higher at the end of the twentyfirst century, the more the "extra emission space" generated by ocean heat uptake is used; see Figs. 1 and 3. Since the atmospheric life times of many of the important 


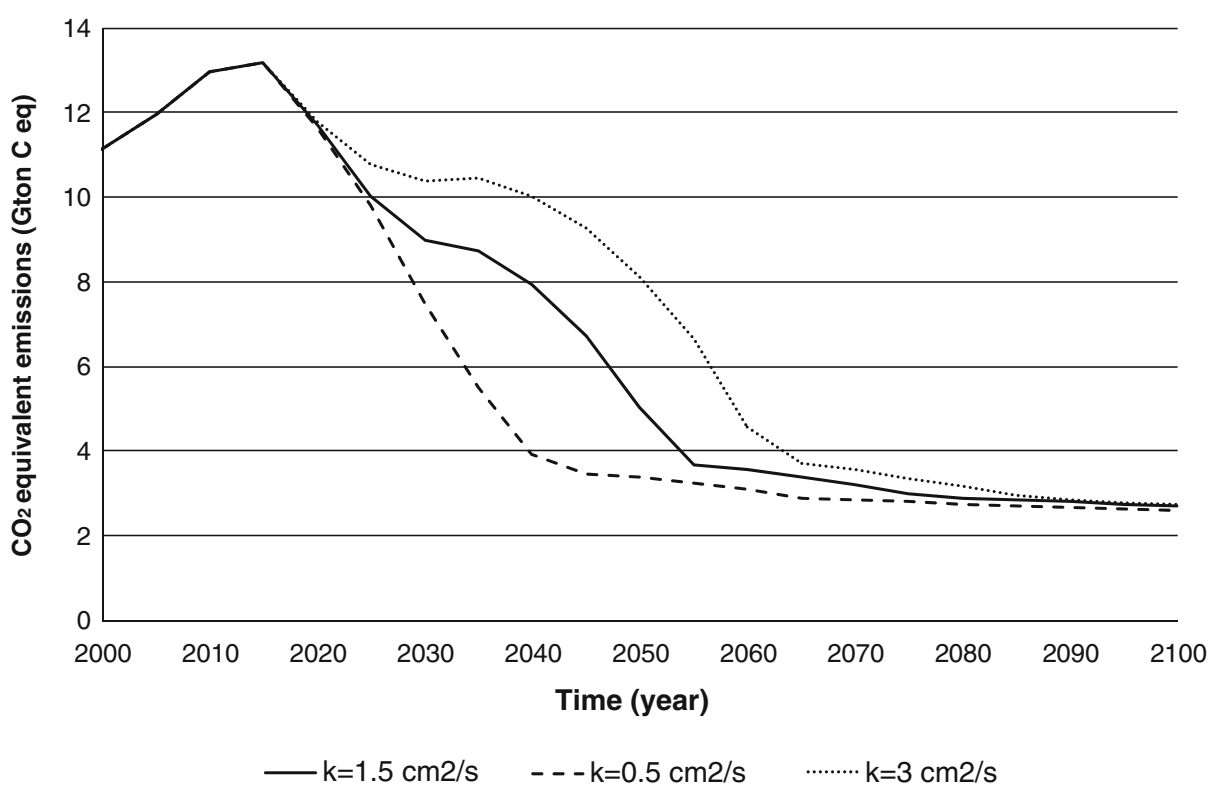

Fig. $3 \mathrm{CO}_{2}$ equivalent emissions of $\mathrm{CO}_{2}, \mathrm{CH}_{4}$, and $\mathrm{N}_{2} \mathrm{O}$ leading to a $2 \mathrm{~K}$ stabilization, with climate sensitivity assumed to be $3 \mathrm{~K}$

greenhouse gases are long, over 100 years, emissions must be slightly lower in subsequent centuries when this "extra emission space" is used in order to stabilize the temperature at a given level and with a given climate sensitivity. However, since the asymptotic cumulative heat uptake increases with increasing diffusivity, more heat will go down into the oceans when the diffusivity is high; see the discussion in Appendix 6. As a consequence, the high emissions in the twenty-first century only need to be compensated for in part in the subsequent centuries.

Note that although the effective heat diffusivity is important in determining emissions levels this century, for a given temperature stabilization limit, it is less important than the climate sensitivity; compare Figs. 3 and 4.

Also note that the numbers presented in this section and Figs. 3 and 4 have to be interpreted with some care since they are based on the use of the GWP concept, which is inappropriate for a more detailed analysis, but they still serve for illustrative purposes.

\subsection{Sensitivity analysis}

\subsubsection{Sensitivity of the level of overshoot with respect to the discount rate}

The discount rate is important for the timing of emissions reductions in a cost minimization model. The higher the discount rate, the more the emissions reductions will be postponed in order to minimize the costs of abatement in net present value terms. As a consequence, one should expect the level of overshoot to increase in the near term in a model such as the one used here, when increasing the discount rate. This is also what we see in the model results; the level of overshoot in 2050 (which 


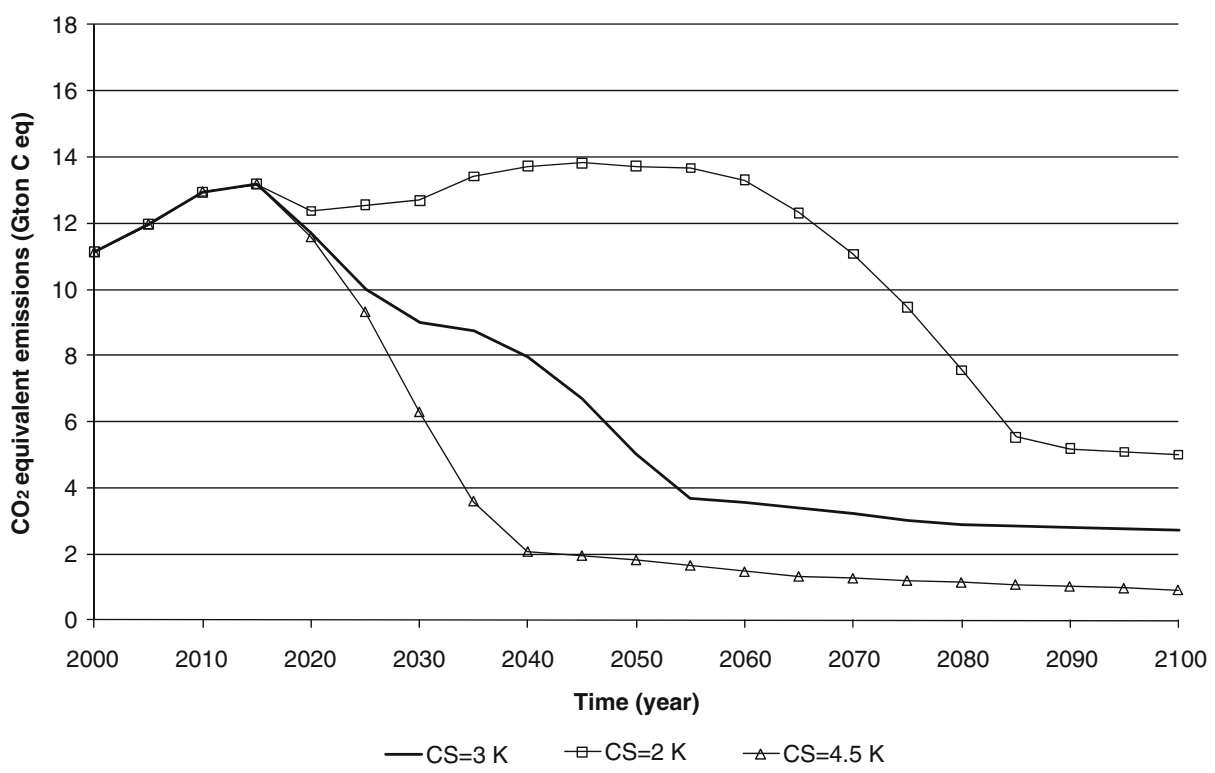

Fig. $4 \mathrm{CO}_{2}$ equivalent emissions of $\mathrm{CO}_{2}, \mathrm{CH}_{4}$, and $\mathrm{N}_{2} \mathrm{O}$ leading to a $2 \mathrm{~K}$ stabilization, with heat diffusivity assumed to be $1.5 \mathrm{~cm}^{2} / \mathrm{s}$

should be considered near-term in this context) increases with increasing discount rates; see Table 2.

As discussed in Appendix 6, the asymptotic level of the cumulative heat uptake is fixed for a certain temperature limit and effective diffusivity. Hence, increasing levels of overshoot in radiative forcing in the near term (2050) would come at the expense of lower levels of overshoot in the longer term (2100 and 2300). The reason for this is that higher levels of heating in the twenty-first century would imply a higher temperature of the interior and deep ocean at the end of the century. As a consequence, less heat could be taken up by the ocean in subsequent centuries since the asymptotic cumulative heat uptake is fixed for a certain parameterization and temperature limit.

This is also observed, although rather weakly, in the model, see Table 2 . The level of overshoot in 2100 declines slightly with increasing discount rate as expected, while the overshoot in 2300 is in principle independent of the discount rate.

Table 2 The level of radiative forcing overshoot depending on discount rate and effective heat diffusivity

\begin{tabular}{|c|c|c|c|c|c|c|c|c|c|}
\hline & \multicolumn{9}{|c|}{ Radiative forcing overshoot $\left(\mathrm{W} / \mathrm{m}^{2}\right)$} \\
\hline & \multicolumn{3}{|l|}{2050} & \multicolumn{3}{|l|}{2100} & \multicolumn{3}{|l|}{2300} \\
\hline & $\begin{array}{l}\mathrm{k}= \\
0.5 \mathrm{~cm}^{2} / \mathrm{s}\end{array}$ & $\begin{array}{l}\mathrm{k}= \\
1.5 \mathrm{~cm}^{2} / \mathrm{s}\end{array}$ & $\begin{array}{l}\mathrm{k}= \\
3 \mathrm{~cm}^{2} / \mathrm{s}\end{array}$ & $\begin{array}{l}\mathrm{k}= \\
0.5 \mathrm{~cm}^{2} / \mathrm{s}\end{array}$ & $\begin{array}{l}\mathrm{k}= \\
1.5 \mathrm{~cm}^{2} / \mathrm{s}\end{array}$ & $\begin{array}{l}\mathrm{k}= \\
3 \mathrm{~cm}^{2} / \mathrm{s}\end{array}$ & $\begin{array}{l}\mathrm{k}= \\
0.5 \mathrm{~cm}^{2} / \mathrm{s}\end{array}$ & $\begin{array}{l}\mathrm{k}= \\
1.5 \mathrm{~cm}^{2} / \mathrm{s}\end{array}$ & $\begin{array}{l}\mathrm{k}= \\
3 \mathrm{~cm}^{2} / \mathrm{s}\end{array}$ \\
\hline $\mathrm{R}=2 \%$ & 0.59 & 0.81 & 1.01 & 0.49 & 0.73 & 0.98 & 0.34 & 0.39 & 0.45 \\
\hline$r=4 \%$ & 0.64 & 0.97 & 1.21 & 0.49 & 0.70 & 0.92 & 0.34 & 0.39 & 0.45 \\
\hline$r=6 \%$ & 0.67 & 1.07 & 1.33 & 0.48 & 0.70 & 0.91 & 0.34 & 0.39 & 0.45 \\
\hline
\end{tabular}


The level of overshoot is more sensitive to the value of the discount rate, the higher the effective heat diffusivity is. The reason for this is that the higher the diffusivity is, the larger is both the rate of the uptake of heat by the oceans and the asymptotic cumulative heat uptake. In consequence, the flexibility of the radiative forcing pathway leading to a stabilization of the temperature is enhanced the higher the diffusivity. This flexibility is in turn exploited in the economic model in order to minimize the NPV abatement costs.

\subsubsection{Sensitivity of the level of overshoot with respect to the baseline scenario}

The model is also run with a different baseline scenario in order to corroborate the robustness of the results. The IIASA B2 scenario, which is an updated version of SRES B2; see Riahi et al. (2006) and IIASA (2009) is used as an alternative baseline scenario. The B2 scenario can be characterized as a 'dynamics as usual' rates of change scenario. Compared to the A2r scenario, it includes lower population growth, higher per capita economic growth and lower level of greenhouse gas emissions, see Riahi et al. (2006) and IIASA (2009) for details.

Baseline emissions beyond 2100 are assumed to remain constant, except that fossil $\mathrm{CO}_{2}$ baseline emissions will eventually decline due to the constraint that the cumulative carbon emissions from fossil sources cannot exceed $5000 \mathrm{G}$ ton $\mathrm{C}$ due to limitations on extractable fossil fuel resources.

The same marginal abatement cost functions are used as in the base case; note though that the marginal abatement cost depends on the relative abatement of the baseline emissions, implying that the marginal abatement costs and total abatement

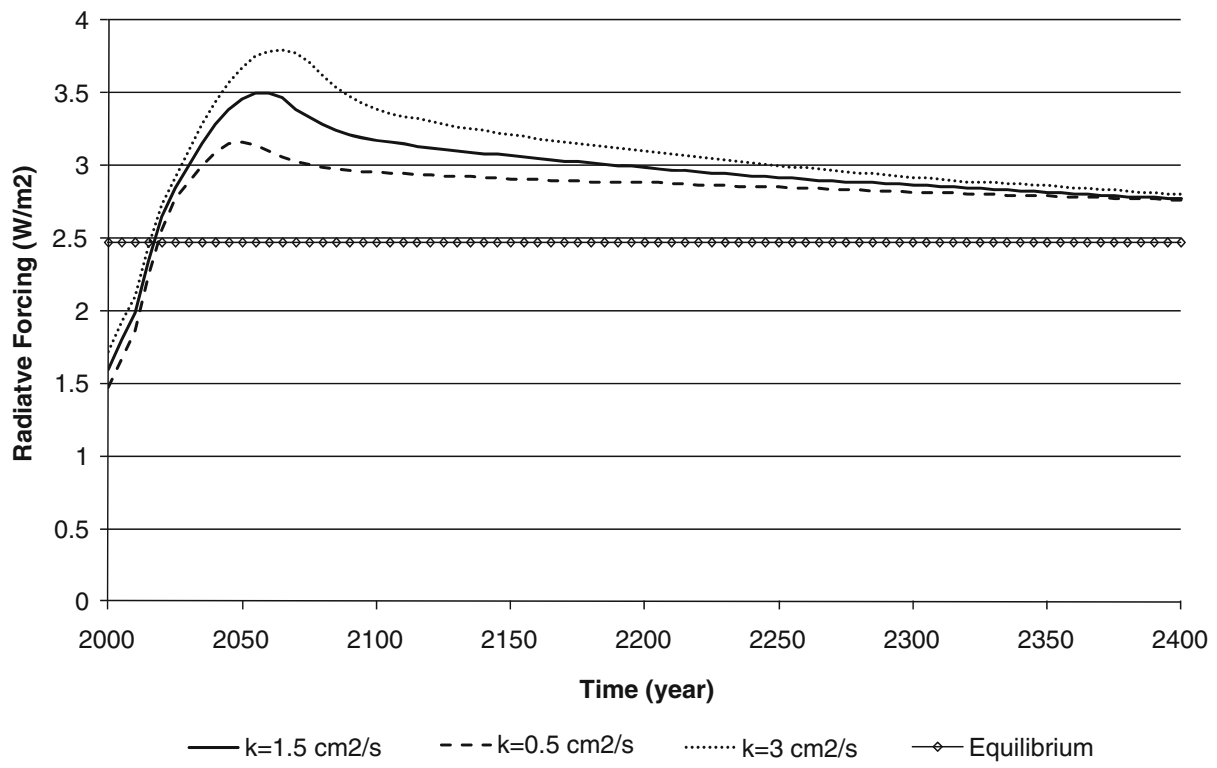

Fig. 5 Radiative forcing pathways (net of gases and aerosols) generated with the B2 baseline scenario leading to a stabilization of the temperature at $2 \mathrm{~K}$, given a climate sensitivity of $3 \mathrm{~K}$ and no temperature overshoot 
Fig. 6 Radiative forcing level (net of greenhouse gases and aerosols) in 2050 for pathways leading to a temperature stabilization level at $2 \mathrm{~K}$ above the pre-industrial level. The solid line shows the equilibrium radiative forcing for stabilizing the temperature at $2 \mathrm{~K}$, while the dots illustrate results from the MiMiC model

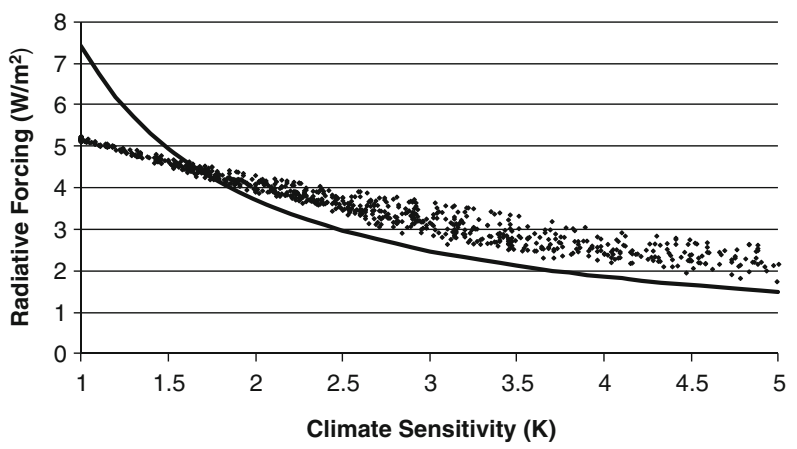

costs of reducing a certain absolute amount of emissions will differ between the two scenarios.

As seen in Fig. 5, the radiative forcing profile generated with the B2 scenario and a $2 \mathrm{~K}$ target will be close to identical to the result using the A2r scenario as baseline scenario, see in Fig. 1. The difference between the radiative forcing in each year and for each assumption on the effective diffusivity is less $0.08 \mathrm{~W} / \mathrm{m}^{2}$. Beyond year 2100 the difference in each year is less $0.01 \mathrm{~W} / \mathrm{m}^{2}$. The reason for the small difference between the different baseline scenarios is that given current emissions and atmospheric stock of greenhouse gases together with the constraint on how fast emissions may decline and the $2 \mathrm{~K}$ target, the forcing profile and emissions levels (generated with a cost minimization approach) are to a large extent determined by the geophysical factors such as the climate sensitivity, effective diffusivity and the carbon cycle. The forcing profile and emissions levels depend to a lesser degree on the details of the baseline emissions scenario and abatement costs (given reasonable assumptions on these).

\subsection{Monte Carlo analysis}

The Monte Carlo runs are used to estimate and illustrate the relative importance of the uncertainty in climate sensitivity to that of the uncertainty in effective heat

Fig. 7 Radiative forcing level (net of greenhouse gases and aerosols) in 2100 for pathways leading to a temperature stabilization level at $2 \mathrm{~K}$ above the pre-industrial level. The solid line shows the equilibrium radiative forcing for stabilizing the temperature at $2 \mathrm{~K}$, while the dots illustrate results from the MiMiC model

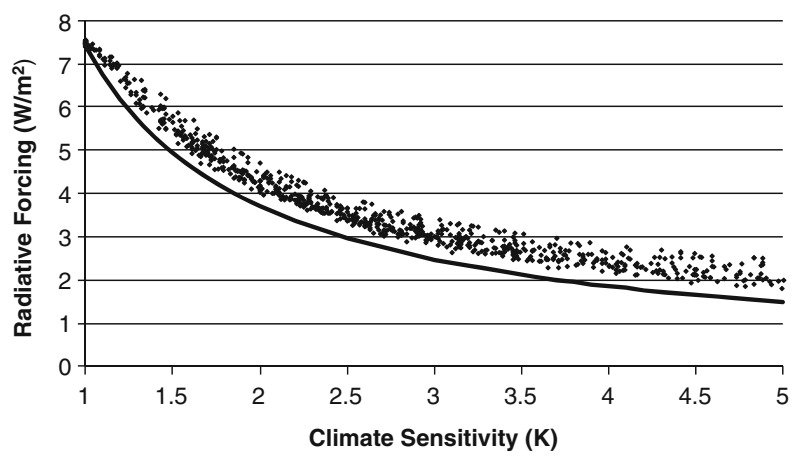


Fig. 8 Radiative forcing level (net of greenhouse gases and aerosols) in 2300 for pathways leading to a temperature stabilization level at $2 \mathrm{~K}$ above the pre-industrial level. The solid line shows the equilibrium radiative forcing for stabilizing the temperature at $2 \mathrm{~K}$, while the dots illustrate results from the MiMiC model

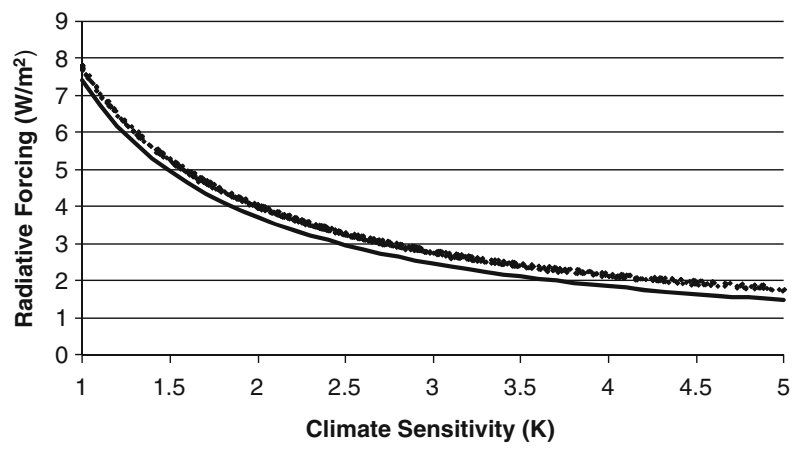

diffusivity, in determining levels of radiative forcing in 2050, 2100, and 2300 and the NPV stabilization abatement cost. The analyses and presentation of the results are limited to climate sensitivities below $5 \mathrm{~K}$ per $\mathrm{CO}_{2}$ eq. doubling. Very few feasible solutions are generated for higher climate sensitivities and a stabilization target of $2 \mathrm{~K}$ above the pre-industrial level.

\subsubsection{Radiative forcing overshoot in 2050, 2100, and 2300}

In Figs. 6, 7, and 8, the net radiative forcing of anthropogenic agents considered in the model in 2050, 2100, and 2300 are plotted and compared with equilibrium radiative forcing for a range of climate sensitivity values when the global average surface temperature is stabilized at $2 \mathrm{~K}$ above the pre-industrial level.

For high and medium level climate sensitivities, there are large overshoots in the radiative forcing above the equilibrium level in both 2050 and 2100, while, on average, smaller ones in 2300. This is in line with the results presented in Fig. 1 and discussed in Section 3.1. When the climate sensitivity is above $2 \mathrm{~K}$ per $\mathrm{CO}_{2}$ eq. doubling (which it is likely to be according to Meehl et al. (2007)), the level of overshoot is, in general, above $0.2 \mathrm{~W} / \mathrm{m}^{2}$ (for low heat diffusivities) and up to about $1 \mathrm{~W} / \mathrm{m}^{2}$ (for high diffusivities), in both 2050 and 2100. In 2300, the forcing overshoot range is much smaller, and the overshoot is about $0.3 \mathrm{~W} / \mathrm{m}^{2}$ and not strongly dependent on diffusivity; see also the results in Section 3.1. ${ }^{4}$

For climate sensitivity values below $1.5 \mathrm{~K}$ per $\mathrm{CO}_{2}$ eq. doubling (which the climate sensitivity is very likely not to be according to Meehl et al. (2007)), the level of overshoot is relatively small in 2100 because the maximum overshoot takes place between 2100 and 2300. For these cases with low climate sensitivity values, the radiative forcing level is below the long-run equilibrium level in 2050 since the baseline emissions result in a radiative forcing that is below the long-run equilibrium level, see Fig. 6.

\footnotetext{
${ }^{4}$ For the stabilization level required to meet the $2 \mathrm{~K}$ target with a climate sensitivity of $3 \mathrm{~K}$, an overshoot of $1 \mathrm{~W} / \mathrm{m}^{2}$ corresponds roughly to an overshoot of $90 \mathrm{ppm} \mathrm{CO}$ equivalent concentration. For low climate sensitivities $(2 \mathrm{~K})$, an overshoot of $1 \mathrm{~W} / \mathrm{m}^{2}$ corresponds to roughly $115 \mathrm{ppm} \mathrm{CO}_{2}$ equivalent concentration, while for high climate sensitivities $(4.5 \mathrm{~K})$, the corresponding number is about $80 \mathrm{ppm} \mathrm{CO}_{2}$ equivalent concentration.
} 


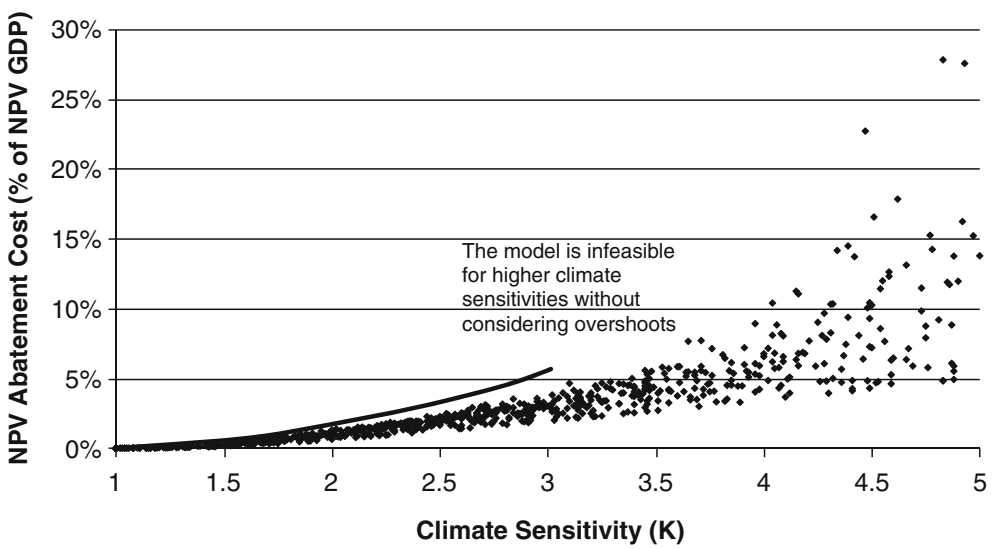

Fig. 9 NPV cost of stabilizing the temperature at $2 \mathrm{~K}$ above the pre-industrial level as a function of climate sensitivity. The spread (of the dots) is due to differences in ocean heat uptake, while the solid line is the NPV cost for stabilization at the equilibrium radiative forcing level, without overshoot

Note that the relative overshoot (radiative forcing divided by the equilibrium radiative forcing) increases with climate sensitivity, see Figs. 6, 7, and 8. Measured in relative terms, the level of radiative forcing overshoot above its long-run equilibrium level is $20 \%$ to $60 \%$ for high levels of climate sensitivity (i.e., about $4.5 \mathrm{~K}$ ) and $8 \%$ to $30 \%$ for low values of climate sensitivity (i.e., about $2 \mathrm{~K}$ ) in 2100 . This is related to the result that the time to reach a certain fraction of the equilibrium warming (often measured as the e-folding time) grows with climate sensitivity, see Hansen et al. (1985), Wigley and Schlesinger (1985) and Harvey (1986).

\subsubsection{Net present value abatement cost}

As illustrated in Figs. 3 and 4, climate sensitivity is more important than effective heat diffusivity for determining necessary emissions reductions in the coming century. In line with this, the net present value abatement cost of stabilizing the global average surface temperature at the $2 \mathrm{~K}$ limit is strongly related to climate sensitivity and to a lesser degree to effective heat diffusivity, see Fig. 9 where the twenty-first century NPV abatement cost as share as the NPV of global baseline GDP over the twentyfirst century as obtained in the A2r scenario (IIASA 2009) is shown. The importance of the effective heat diffusivity can be seen in the spread of the NPV costs for each and every value of the climate sensitivity. For each given climate sensitivity value, low (high) values for the effective heat diffusivity result in NPV abatement costs that are in the upper (lower) contour of the spread in Fig. 9.5

Note that the NPV costs become more sensitive to the value of the heat diffusivity, the higher the climate sensitivity value. The mechanism behind this result is not

\footnotetext{
${ }^{5}$ The economic module is simple, and the numbers should be interpreted as order of magnitude estimates. The GDP scenario used here is exogenous, however, the approximation of using an exogenous scenario becomes gradually less accurate the higher the abatement costs.
} 
obvious but is related to the timing of emission reductions and the convexity characteristics of the discount factor and the abatement costs. ${ }^{6}$

As seen in Fig. 9 and discussed above, the cost of stabilizing the temperature is influenced by the effective heat diffusivity. What is perhaps more important from a policy perspective is that, irrespective of the level of diffusivity, the cost of temperature stabilization including (a small or a large) overshoot in radiative forcing is considerably lower than the cost of stabilizing the radiative forcing at its equilibrium level without any overshoot, see Fig. 9. Relatedly, a 2 K target would not be physically attainable for a large range of possible climate sensitivity values without overshoots in radiative forcing.

\section{Discussion and conclusion}

Radiative forcing and emissions pathways for, and NPV costs of, stabilizing the global average surface temperature at $2 \mathrm{~K}$ above the pre-industrial level have been analyzed. The main aim has been to understand the role of ocean heat uptake and how this uptake affects the possibility for radiative forcing profiles that temporarily overshoot the equilibrium level associated with a given limit on global average temperature and climate sensitivity. We have found that the level of overshoot increases with increasing effective heat diffusivity. For high diffusivity values, the overshoot can remain above $1 \mathrm{~W} / \mathrm{m}^{2}$ over the present century and decline over the subsequent centuries. As late as 2300 , the level of overshoot in the model is, in general, above $0.3 \mathrm{~W} / \mathrm{m}^{2}$ for a wide range of heat diffusivity and climate sensitivity values. While the level of overshoot during the present century strongly depends on the level of the effective heat diffusivity, the level of overshoot in the long-run does not. Although not explicitly analyzed in this paper, the long-term overshoot in radiative forcing is strongly dependent on the warming of the water downwelling into the deep oceans. The general results that the radiative forcing overshoot may be both substantial and persistent hold when the discount rate is altered and when a different baseline scenario is used.

In addition, although the effective heat diffusivity is important for radiative forcing and emissions pathways and the corresponding NPV abatement costs, the heat diffusivity is less important than the climate sensitivity in determining these

\footnotetext{
${ }^{6}$ The mechanisms can be understood with the aid of Figs. 6, 7, and 8. The level of radiative forcing overshoot is roughly independent of climate sensitivity for sensitivities above $2 \mathrm{~K}$. When climate sensitivity is high (low), the concentration levels will be comparably low (high); consequently emissions need to be reduced more and at an earlier date, the higher the climate sensitivity. In addition, both the discounting factor (which declines geometrically with time) and the abatement cost functions are convex. Also, the marginal cost increases at a higher rate, the higher the level of abatement. Given that emissions need to be reduced more and at an earlier date when climate sensitivity is high, the NPV cost becomes more sensitive to (small) changes in the emissions level that follow from different assumptions on the effective diffusivity. This effect is somewhat weakened by the fact that the relationships of concentration to radiative-forcing, for the three main greenhouse gases $\mathrm{CO}_{2}$, $\mathrm{CH}_{4}$, and $\mathrm{N}_{2} \mathrm{O}$, are concave. Given concavity of the radiative forcing functions, the marginal radiative forcing (usually referred to as radiative efficiency) decreases with concentration, which implies that for an equal overshoot in radiative forcing, the additional "emissions opportunity" caused by this overshoot is smaller the lower level of concentrations. Still, the convexity characteristics of the abatement cost and discounting are more important in determining the NPV abatement cost.
} 
variables. However, due to non-linearities in the economic system (i.e., pertaining to the marginal abatement cost functions and discounting) the importance of the value of the effective heat diffusivity for the NPV stabilization cost increases with increasing climate sensitivity.

The results in this study concerning the level and duration of the overshoot may not directly be applicable to stabilization targets for the global average surface temperature higher than the $2 \mathrm{~K}$ limit. The possible non-linearities in the climate system, such as the climate sensitivity and the ocean circulation, become progressively more important the more the climate is changing, see for example Randall et al. (2007) and Knutti and Hegerl (2008).

In this study, we have only analyzed the role of the effective heat diffusivity for the global mean surface temperature change. The importance of the heat uptake for thermal expansion of the oceans has not been assessed in detail. A higher diffusivity implies that more heat will be taken up by the oceans; consequently the thermal expansion of the oceans will be more pronounced. Given the strong correlation between cumulative heat uptake and thermosteric sea level rise, the relative difference in thermosteric sea level rise that follows from an increase of global average surface temperature of $2 \mathrm{~K}$ between the high $\left(\mathrm{k}=3 \mathrm{~cm}^{2} / \mathrm{s}\right)$ and low $\left(\mathrm{k}=0.5 \mathrm{~cm}^{2} / \mathrm{s}\right)$ diffusivity is roughly about two. ${ }^{7}$ This effect on the sea level rise runs contrary to the socially advantageous aspects a high effective heat diffusivity has on the cost of stabilization and on necessary emission reductions in the coming decades when meeting a temperature stabilization target.

Also, overshoot scenarios as such enhance the risk for dangerous climate change relative to direct stabilization without overshoot as discussed by O'Neill and Oppenheimer (2004) and Schneider and Mastrandrea (2005). Radiative forcing overshoot scenarios imply a higher rate of temperature change and an enhanced risk for temperature overshoots when compared to scenarios that directly stabilize at the equilibrium radiative forcing associated with a certain climate sensitivity and global temperature target. On the other hand, overshoot scenarios reduce the NPV cost of stabilization considerably. These risk-benefit trade-offs need to be studied further.

The majority of integrated assessment models are programmed to meet concentration or radiative forcing targets by 2100 . We show that the level of radiative forcing overshoot may still be substantial in 2100 and beyond, for a $2 \mathrm{~K}$ limit. This implies that models set to meet a radiative forcing target based on a temperature limit and a given climate sensitivity are likely to overstate the necessary emissions reductions during the twenty-first century as well as stabilization abatement costs. However, these integrated assessment models do not in general take into account effects which should lead to a smaller emissions space over the present century, for example climate-carbon cycle feedbacks and positive albedo feedbacks not included in climate sensitivity. Hence, climate dynamics and those feedbacks not included in climate sensitivity may need to be better represented in these models.

The direct policy implications of the results are that concentration or radiative forcing stabilization without overshoot is an excessively costly approach to formulating climate targets; see also den Elzen and van Vuuren (2007). Economically, it

\footnotetext{
${ }^{7}$ The increase in the oceans' energy content is roughly a factor two higher in the high diffusivity case than in the low diffusivity case; see Appendix 5 and 6.
} 
makes much more sense to accept a level of radiative forcing overshoot above a longrun stabilization level. As argued by Allen et al. (2009), overshoot targets may be complicated to formulate since the uncertain degree and duration of the overshoot has to be settled; they suggest cumulative $\mathrm{CO}_{2}$ emissions targets which have fewer degrees of freedom. However, as they briefly discuss, cumulative targets based on $\mathrm{CO}_{2}$-equivalent emissions are not especially suitable for non- $\mathrm{CO}_{2}$ greenhouse gases such as methane, due to the large differences in the atmospheric life time of the different greenhouse gases. The aim of this paper has been to present information about the degree and duration of overshoots consistent with a $2 \mathrm{~K}$ limit. Within the scope of this analysis, these overshoots are found to be both persistent and rather large. However, the model approach in this paper is simple, and more studies are needed to challenge the results presented in order to understand if these results are robust or model dependent. Also, more research is needed on how best to tackle the issue of overshoot targets and cumulative emissions targets, given the multi-gas approach to climate change mitigation.

Finally, as always concerning climate change and integrated assessment models, the calculations are inherently uncertain due to both parametric and structural uncertainties and immense simplifications of the integrated economic and geophysical system. Processes that govern ocean mixing are unduly complicated and hard to represent even in AOGCMs. However, eventhough the energy balance model used here, which is based on an upwelling diffusion model, is a highly aggregated approach it may still be useful. An indication of this is the frequent use of upwelling diffusion energy balance models in the IPCC WG1 assessment reports. Consequently, even if the results should be interpreted with care, they illustrate the important role of ocean heat uptake for radiative forcing pathways, the necessary greenhouse emissions reductions over the coming centuries, and abatement costs if the global mean surface temperature is to be stabilized at $2 \mathrm{~K}$ above the pre-industrial level.

Acknowledgements I would like to acknowledge Christian Azar and Martin Persson for their collaboration on the construction of the original version of the MiMiC model. Many thanks to Christian Azar, Paulina Essunger, Fredrik Hedenus, Sten Karlsson, Martin Persson, Henning Rodhe and three anonymous reviewers for comments on earlier drafts of this paper. Funding from the Swedish Energy Agency and Göteborg Energi Research Foundation is gratefully acknowledged.

Open Access This article is distributed under the terms of the Creative Commons Attribution Noncommercial License which permits any noncommercial use, distribution, and reproduction in any medium, provided the original author(s) and source are credited.

\section{Appendix 1-Upwelling diffusion energy balance model}

To analyze the role of ocean heat uptake for emissions and radiative forcing pathways leading to temperature stabilization, a linear Upwelling Diffusion Energy Balance Model (UDEBM) has been used. UDEBMs have been used extensively for analyzing the effect of increased levels of radiative forcing on global average surface temperature change and sea level rise; see Hoffert et al. (1980) and Harvey and Schneider (1985) for early examples. UDEBMs have also been reported to successfully emulate the global average surface temperature response of AOGCMs (Schlesinger and Jiang 1990; Raper et al. 2001; Meinshausen et al. 2008).

The model is heavily parameterized: climate sensitivity, effective heat diffusivity, upwelling rates, and the relative change in the temperature of the downwelling polar 
water to that of the global average surface ocean temperature are all prescribed. Further, the model is assumed to be linear and time invariant, hence all parameters remain constant over time and are independent of the state of the climate. However, complex AOGCMs usually show a decline in ocean circulation for increases in global average surface temperature and an increase in effective climate sensitivity, over time as well as for higher increases in the global average surface temperature. However, these effects are limited when considering a relatively small increase in the global average surface temperature, as we do in the stabilization scenarios; see Raper et al. (2001), Randall et al. (2007) and Knutti and Hegerl (2008).

The model divides the surface of the globe in two parts, one part for the ocean and the troposphere above it and one part for the land surface and troposphere above it. The heat capacity of the land surface and the troposphere above is small and set to zero, as in Raper et al. (2001), Wigley and Raper (2001) and Meinshausen et al. (2008).

In the standard set-up, climate sensitivity is set to $3 \mathrm{~K}$ for a doubling of the atmospheric $\mathrm{CO}_{2}$ stock, the upwelling rate to $4 \mathrm{~m} /$ year, and the heat diffusivity to $1.5 \mathrm{~cm}^{2} / \mathrm{s}$, with two main alternatives, 0.5 and $3 \mathrm{~cm}^{2} / \mathrm{s}$. The equilibrium temperature change is assumed to be $30 \%$ higher for the surface air over land than over the ocean surface, in line with Meinshausen et al. (2009). See Joshi et al. (2008) for a discussion of the mechanisms behind the land/ocean temperature contrast. Further, we take into account that the marine surface air temperature increase is higher than the ocean surface temperature increase due to retreating sea ice cover by assuming that the air temperature increase is $30 \%$ higher than the sea surface temperature increase, in line with Raper et al. (2001). These assumptions are basically standard assumptions in UD-EBMs and similar models; see Hoffert et al. (1980), Raper et al. (2001), Shine et al. (2005), Meinshausen et al. (2008, 2009) and Baker and Roe (2009).

The model is discretized over time and over the depth of the interior and deep ocean. The surface layer of the ocean is assumed to be $70 \mathrm{~m}$, while the interior ocean is divided into 30 identical layers of $130 \mathrm{~m}$ each. For the numerical integration, an Euler scheme with a time step of 0.2 years is used. The choice of time step and ocean layer thickness results in numerical stability.

\section{Appendix 2-Calibration of the three box energy balance model to the upwelling diffusion energy balance model}

Calibrating response functions from climate models such as AOGCMs or UDEBMs is a common and simple approach for taking into account the thermal inertia in aggregate models. This is a suitable approach because for any linear and timeinvariant system, the dynamics of the system can be described by the impulse response function. Even though the climate system is not linear and time-invariant, we may in our case reasonably assume that the global average surface temperature change is time-invariant and linear in radiative forcing; see Appendix 1. The reason is that we constrain the global average surface temperature to $2 \mathrm{~K}$ above the preindustrial level and the potential non-linearities become more important for larger changes in the global average surface temperature.

So as to keep the response function tractable, the number of exponential terms in the response function should be as small as possible but still give an accurate response for the system. Jarvis and Li (2010) argue that the sum of three exponential 


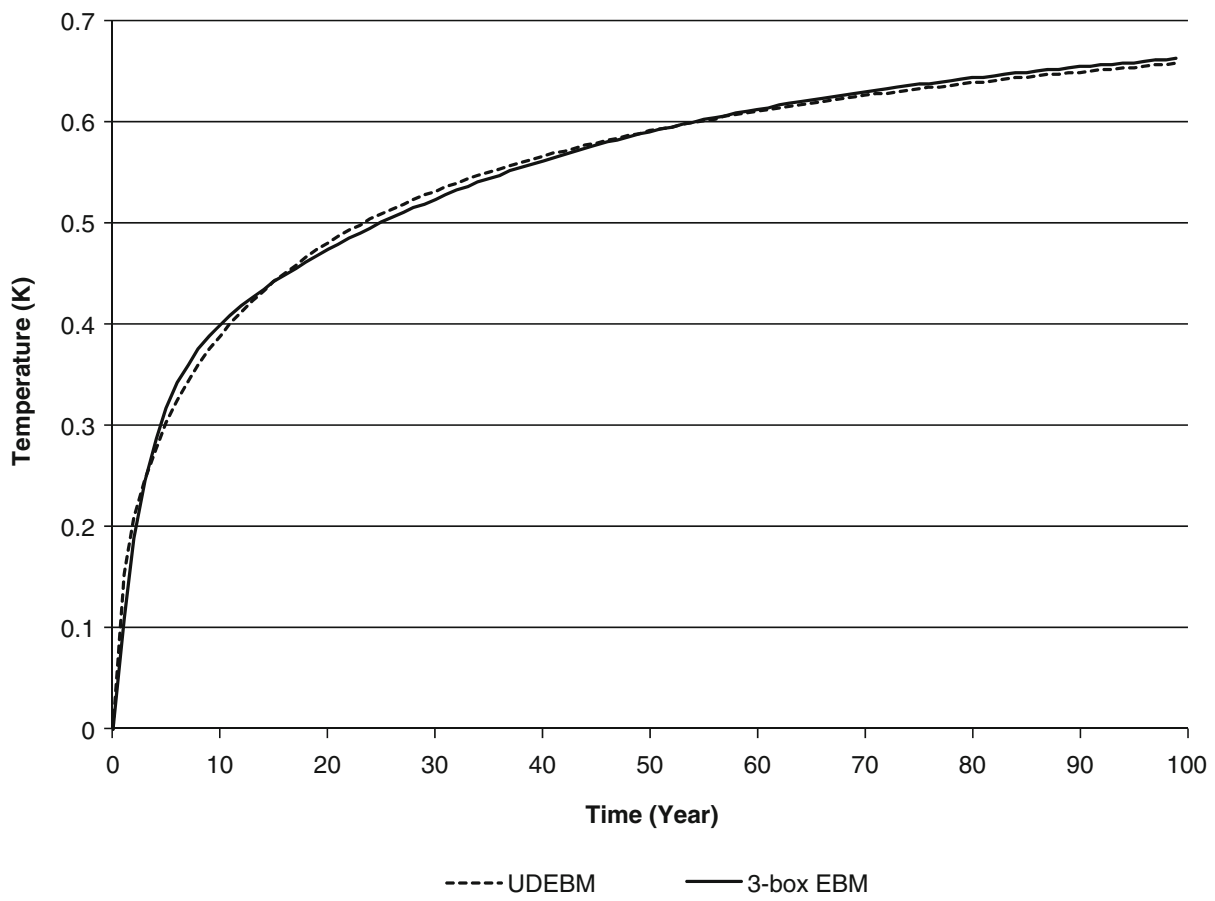

Fig. 10 Comparison of the temperature response of the UDEBM and the calibrated three-box EBM for the first 100 years for a $1 \mathrm{~W} / \mathrm{m}^{2}$ step in radiative forcing. The climate sensitivity is set to $3 \mathrm{~K}$. For comparison, the equilibrium temperature change to a $1 \mathrm{~W} / \mathrm{m}^{2}$ step is $0.81 \mathrm{~K}$

terms with three corresponding time constants emulates the temperature response of UDEBMs and AOGCMs. Further, both Grieser and Schönwise (2001) and Li and Jarvis (2009) successfully emulate the temperature response of AOGCMs with this approach. This is also our starting point. However, since this three-term impulse response function is numerically equivalent to a differential model with three boxes we choose to calibrate a three-box EBM to the UDEBM; see Li and Jarvis (2009), Grieser and Schönwiese (2001) and Hooss et al. (2001) for similar approaches.

Figure 10 illustrates the fit between the global average surface temperature generated by the three box model and the UDEBM following a $1 \mathrm{~W} / \mathrm{m}^{2}$ step in the radiative forcing and a climate sensitivity of $3 \mathrm{~K}$ and an ocean heat diffusivity of $1.5 \mathrm{~cm}^{2} / \mathrm{s}$. The (relative) root mean square error of the three-box EBM to the UDEBM over a time horizon of 100 years is about $1 \%$, and the error declines with longer time horizons. Also, as presented in Appendices 4 and 5, the model gives reasonable results when calibrating the aerosol forcing from historical radiative forcing and temperature data, and when initializing the heat content of the oceans.

\section{Appendix 3-Carbon cycle}

To model the net land and ocean uptake of $\mathrm{CO}_{2}$, two different response functions are applied. One response function is linearised around an atmospheric $\mathrm{CO}_{2}$ level of 325 ppm and the other around 450 ppm; see Harvey (1989) and Wigley (1991) for 
Table 3 Pulse response representation of the carbon cycle, parameters

\begin{tabular}{llllllll}
\hline $\mathrm{CO}_{2}(\mathrm{ppm})$ & $a_{0}$ & $a_{1}$ & $a_{2}$ & $a_{3}$ & $\tau_{1}$ & $\tau_{2}$ & $\tau_{3}$ \\
\hline 325 & 0.171 & 0.178 & 0.402 & 0.249 & 139.9 & 16.6 & 2.9 \\
450 & 0.171 & 0.178 & 0.402 & 0.249 & 515.8 & 30.5 & 3.1 \\
\hline
\end{tabular}

similar approaches. The latter function is applied for time periods after year 2005 and the former is applied to time periods prior to 2005. These two linear impulse response functions are calibrated from the non-linear impulse response functions given in Joos et al. (1996) and Tanaka (2008); see Eq. 4 and Table 3. For the calibration of our response functions, the carbon fertilization factor $\beta$ is set to 0.25 , and the carbon fertilization is logarithmically dependent on the atmospheric $\mathrm{CO}_{2}$ concentration.

$$
\Delta C=a_{0}+\sum_{i=1}^{3} a_{i} \cdot e^{-t / \tau_{i}}
$$

A range of papers have pointed to the fact that the ocean and land/biomass sink of carbon is strongly tied to the state of the climate with the effect that the net uptake of carbon in oceans and land/biomass decreases with increasing global average surface temperature (Friedlingstein et al. 2006; Matthews 2006; Plattner et al. 2008; Frank et al. 2010). To simulate this, we assume that the positive feedback has been negligible up until the present (2005) but will be a factor that needs to be taken into account for global average surface temperature increases greater than about $0.75 \mathrm{~K}$ above the pre-industrial level (the initial global average surface temperature in the optimization). We assume that $10 \mathrm{ppm} \mathrm{CO}_{2}$ is added to the atmosphere for every degree $\mathrm{C}$ increase in global average surface temperature above the 2005 level. This is estimated from results presented in Matthews (2006), Plattner et al. (2008), Thorn and Harte (2006) and Frank et al. (2010).

\section{Appendix 4-Calibration of net aerosol forcing}

The calibration of the net aerosol strength gives a forcing in line with those presented in Forster et al. (2007); see Fig. 11. ${ }^{8}$ Similar to results presented in other papers (e.g., Andreae et al. 2005) there is a strong statistical correlation between climate sensitivity and net tropospheric aerosol forcing. The higher the climate sensitivity, the more negative the net aerosol forcing has to be in order to emulate the historical temperature. The importance of the ocean heat diffusivity for the calibration of the net aerosol strength can be seen in the spread of the aerosol forcing for a given climate sensitivity. When assuming a low (high) diffusivity in the calibration against historical temperature and forcing data, the estimated net aerosol forcing tends to be in the upper (lower) contour of the relationship between climate sensitivity and net aerosol forcing shown in Fig. 11. The reasons for this is that a low (high) heat diffusivity implies a faster (slower) temperature response and in order to fit the modeled global average surface temperature change to the measured global average

\footnotetext{
${ }^{8}$ The odd distribution of results for the aerosol forcing for a climate sensitivity of $10 \mathrm{~K}$ is a result of that we constrained the upper tail of the log normal distribution of the climate sensitivity to $10 \mathrm{~K}$.
} 


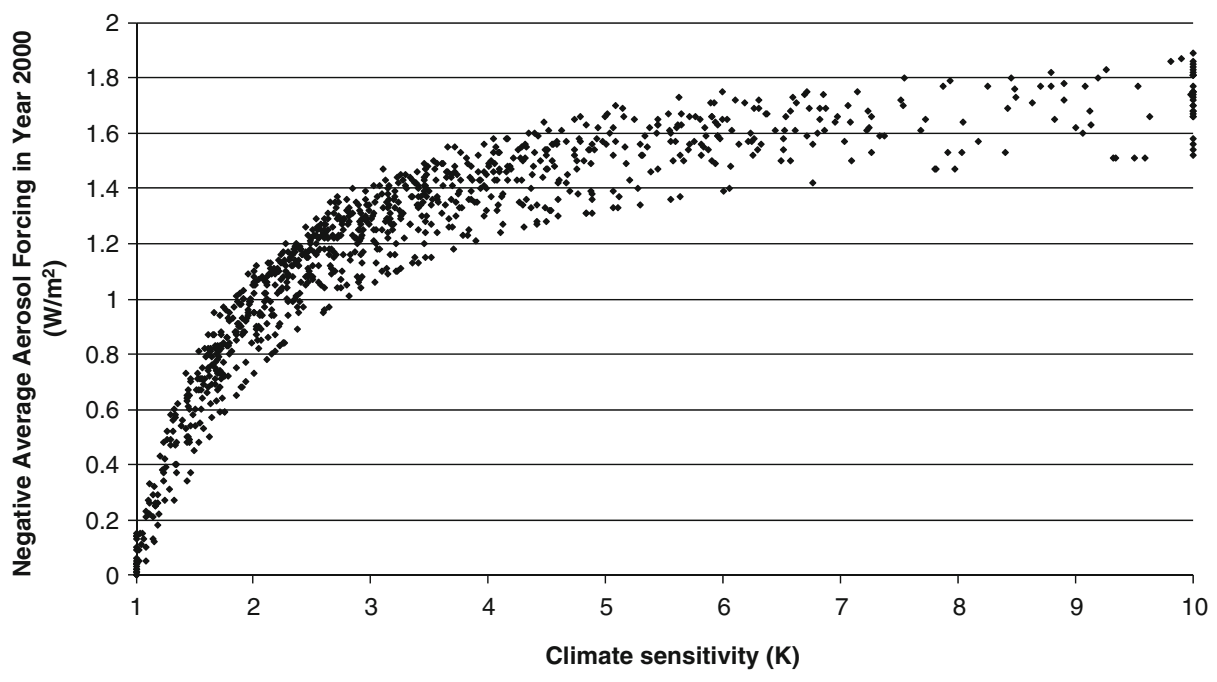

Fig. 11 The net aerosol forcing (including both direct and indirect forcing) that gives the best fit for the modeled global average surface temperature change to the measured temperature change since 1880, given exogenous assumptions on climate sensitivity, heat diffusivity and other major radiative forcing gases/agents

surface temperature above the pre-industrial level the negative net aerosol forcing has to be relatively large (small) for a given value of the climate sensitivity.

\section{Appendix 5-Initialization of ocean heat uptake}

As discussed in Appendix 6 there is a direct link between ocean heat uptake and effective heat diffusivity. The higher the effective heat diffusivity, the more heat is taken up by the oceans for a given period of time and forcing profile, see Fig. 13. This also has implications for the historical uptake of heat by the oceans. The total energy uptake by the climate system between 1961 and 2003 is estimated in Bindoff et al. (2007) to be about $16 \cdot 10^{22} \mathrm{~J}$, where the uptake in the ocean accounts for about $90 \%$ of this, i.e., slightly more than $14 \cdot 10^{22} \mathrm{~J}$. However, more recent analysis points toward higher heat uptake due to changes in the interpretation of measurements. Domingues et al. (2008) present results that the heat uptake between 1961 and 2003 down to a depth of $3,000 \mathrm{~m}$ is $16 \cdot 10^{22} \mathrm{~J}$, and as much as $8 \cdot 10^{22} \mathrm{~J}$ may have been taken up below 3,000 m. However, the number concerning the heat uptake below 3000 is rather speculative. Consequently, low values for the heat diffusivity (less than about $0.5 \mathrm{~cm}^{2} / \mathrm{s}$ ) tend to result in a heat uptake that is too small, while diffusivities above about 4 to $5 \mathrm{~cm}^{2} / \mathrm{s}$ may result in a heat uptake that is too high to match the historical estimates, see Fig. $12 .{ }^{9}$

\footnotetext{
${ }^{9}$ The odd distribution of results for the heat uptake for an effective heat diffusivity of $6 \mathrm{~cm}^{2} / \mathrm{s}$ is a result of that we constrained the upper tail of the log normal distribution of the effective heat diffusivity to $6 \mathrm{~cm}^{2} / \mathrm{s}$.
} 


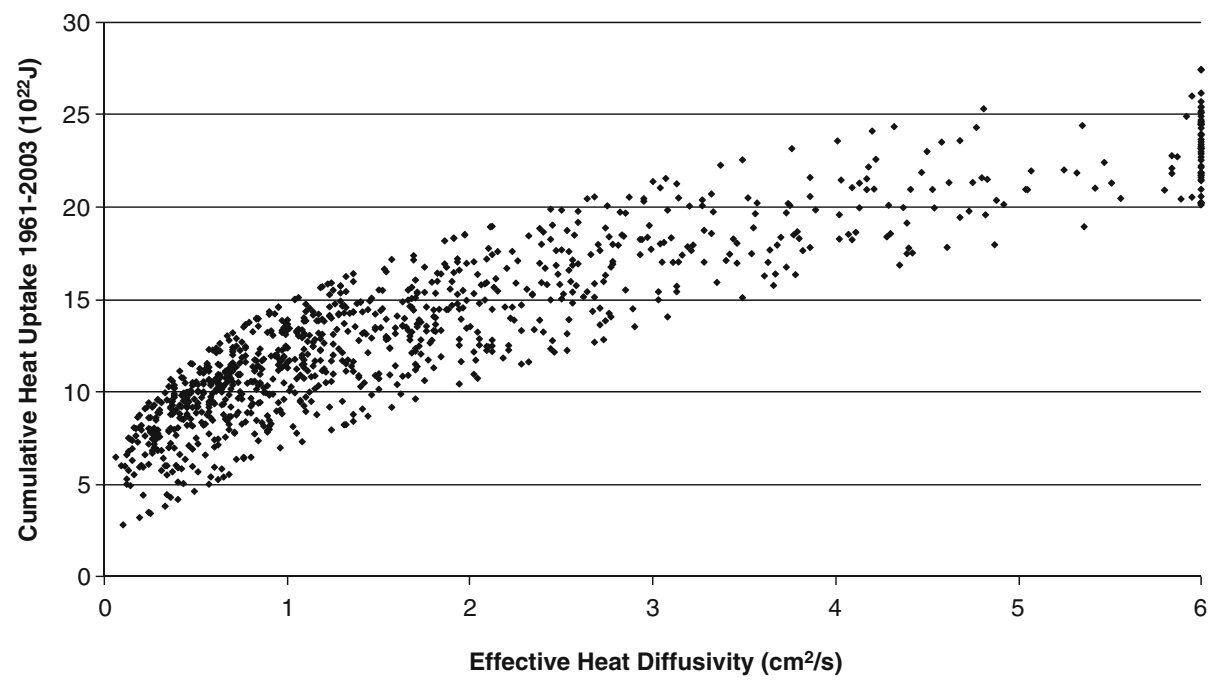

Fig. 12 Net ocean energy uptake generated by the model for the years between 1961 and 2003 as a function of heat diffusivity

\section{Appendix 6-Asymptotic heat uptake}

In this appendix the importance of the effective diffusivity for the ocean heat uptake after a step in the radiative forcing equal to $1 \mathrm{~W} / \mathrm{m}^{2}$ is illustrated and discussed.

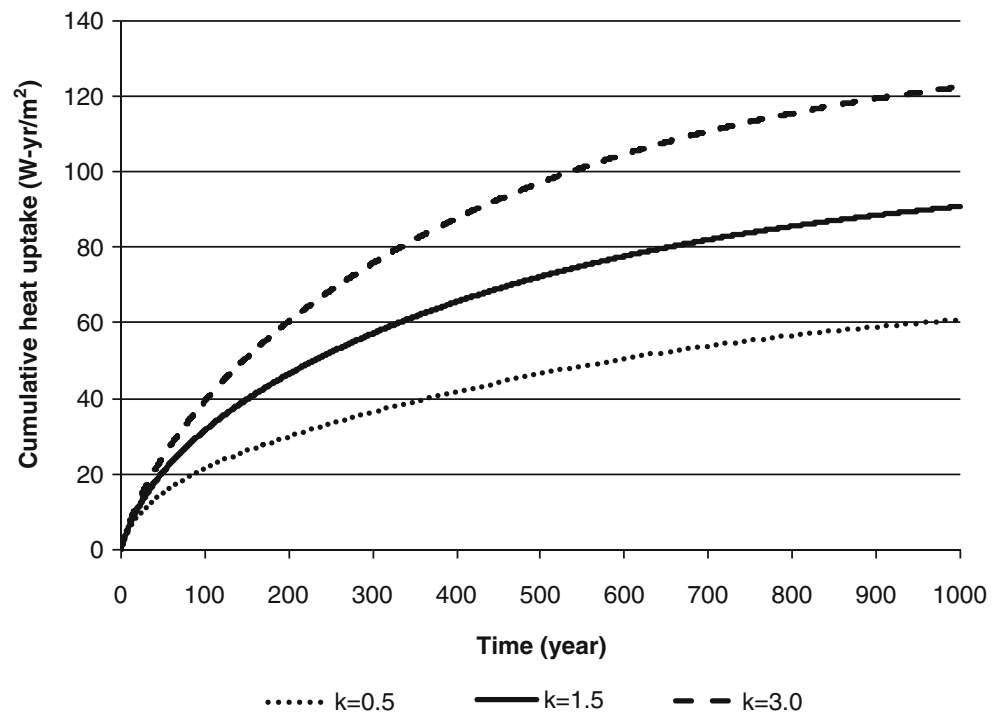

Fig. 13 Cumulative heat uptake by the climate system for a $1 \mathrm{~W} / \mathrm{m}^{2}$ step in radiative forcing and a climate sensitivity of $3 \mathrm{~K}$ 
With heat diffusivity set to $1.5 \mathrm{~cm}^{2} / \mathrm{s}$ and climate sensitivity set to $3 \mathrm{~K}$, about $90 \mathrm{~W}$ year $/ \mathrm{m}^{2}$ have been taken up cumulatively by the ocean after 1,000 years. To reach energy balance with the cumulative forcing of $1,000 \mathrm{~W}$ year $/ \mathrm{m}^{2}$, the remaining $910 \mathrm{~W}$ year $/ \mathrm{m}^{2}$ are due to outgoing heat radiation at the top of the atmosphere. For shorter time horizons, a larger fraction of the forcing is used to heat up the oceans; e.g., over a 200 year time period slightly less than $50 \mathrm{~W}$ year $/ \mathrm{m}^{2}$ is driven into the oceans, while a little more than $150 \mathrm{~W}$ year $/ \mathrm{m}^{2}$ leaves as outgoing radiation. As seen in Fig. 13, the fraction of the energy that is driven down into the oceans is larger the higher the effective heat diffusivity. As a consequence, the global mean surface temperature will increase slower, the higher the diffusivity.

The cumulative heat uptake will asymptotically approach 67, 101 or $136 \mathrm{~W}$ year $/ \mathrm{m}^{2}$, when the effective diffusivity is $0.5,1.5$ or $3 \mathrm{~cm}^{2} / \mathrm{s}$, respectively.

\section{References}

Allan R et al (2007) 2007 Bali climate declaration by scientists. Climate Change Research Centre, University of New South Wales (UNSW), Sydney, Australia. Available online at http://www.ccrc. unsw.edu.au/news/2007/Bali.html

Allen MR, Frame DJ, Huntingford C, Jones CD, Lowe JA, Meinshausen M, Meinshausen N (2009) Warming caused by cumulative carbon emissions towards the trillionth ton. Nature 458:11631166

Andreae MO, Jones CD, Cox PM (2005) Strong Present-day aerosol cooling implies a hot future. Nature 435:1187-1190

Andrews DR, Allen MR (2008) Diagnosis of climate models in terms of transient climate response and feedback response time. Atmos Sci Lett 9:7-12

Azar C, Rodhe H (1997) Targets for stabilization of atmospheric $\mathrm{CO}_{2}$. Science 276:1818-1819

Baker MB, Roe GH (2009) The shape of things to come: why is climate change so predictable? J Climate 22:4574-4589

Bindoff NL, Willebrand J, Artale V, Cazenave A, Gregory J, Gulev S, Hanawa K, Le Quéré C, Levitus S, Nojiri Y, Shum CK, Talley LD, Unnikrishnan A (2007) Observations: oceanic climate change and sea level. In: Solomon S, Qin D, Manning M, Chen Z, Marquis M, Averyt KB, Tignor M, Miller HL (eds) Climate change 2007: the physical science basis. Contribution of Working Group I to the fourth assessment report of the Intergovernmental Panel on Climate Change. Cambridge University Press, Cambridge

BP (2009) BP statistical review of world energy 2009. Available online at via www.bp.com

CDIAC (2010) Carbon dioxide analysis center. Available online at cdiac.ornl.gov

Cubasch U, Meehl GA, Boer GJ, Stouffer RJ, Dix M, Noda A, Senior CA, Raper S, Yap KS (2001) Projections of future climate change. In: Houghton JT, Ding Y, Griggs DJ, Noguer M, van der Linden PJ, Xiaosu D (eds) Climate change 2001: the scientific basis: contribution of Working Group I to the third assessment report of the Intergovernmental Panel on Climate Change (IPCC). Cambridge University Press, Cambridge, p 944

Dasgupta P (2008) Discounting climate change. J Risk Uncertain 37:141-169

den Elzen MGJ, van Vuuren DP (2007) Peaking profiles for achieving long-term temperature targets with more likelihood at lower costs. PNAS 104(46):17931-17936

Domingues CM, Church JA, White NJ, Gleckler PJ, Wijffels SE, Barker PM, Dunn JR (2008) Improved estimates of upper-ocean warming and muti-decadal sea-level rise. Nature 453:10901093

Forest CE, Stone PH, Sokolov AP (2006) Estimated PDFs of climate system properties including natural and anthropogenic forcings. Geophys Res Lett 33:L01705

Forster P, Ramaswamy V, Artaxo P, Berntsen T, Betts R, Fahey DW, Haywood J, Lean J, Lowe G, Myhre DC, Nganga J, Prinn R, Raga G, Schulz M, Van Dorland R (2007) Changes in atmospheric constituents and in radiative forcing. In: Solomon S, Qin D, Manning M, Chen Z, Marquis M, Averyt KB, Tignor M, Miller HL (eds) Climate change 2007: the physical science basis. Contribution of Working Group I to the fourth assessment report of the Intergovernmental Panel on Climate Change. Cambridge University Press, Cambridge 
Frank CD, Esper J, Raible CC, Büntgen U, Trouet V, Stocker B, Joos F (2010) Ensemble reconstruction constraints on the global carbon cycle sensitivity to climate. Nature 463(28): $527-530$

Friedlingstein P, Cox P, Betts R, Bopp L, Von Bloh W, Brovkin V, Cadule P, Doney S, Eby M, Fung I, Bala G, John J, Jones C, Joos F, Kato T, Kawamiya M, Knorr W, Lindsay K, Matthews HD, Raddatz T, Rayner P, Reick C, Roeckner E, Schnitzler KG, Schnur R, Strassmann K, Weaver AJ, Yoshikawa C, Zeng N (2006) Climate-carbon cycle feedback analysis: results from the C4MIP model intercomparison. J Climate 19:3337-3353

Grieser J, Schönwiese CD (2001) Process, forcing and signal analysis of global mean temperature variations by means of a three-box energy balance model. Clim Change 48:617-646

Hansen J, Russell Lacis A, Fung I, Rind D, Stone P (1985) Climate response times: dependence on climate sensitivity and ocean mixing. Science 229(4716):857-859

Hansen J, Nazarenko L, Ruedy R, Sato M, Willis J, Del Genio A, Koch D, Lacis A, Lo K, Menon S, Novakov T, Perlwitz J, Russell G, Schmidt GA, Tausnev N (2005) Earth's energy imbalance: confirmation and implications. Science 308(5727):1431-1435

Harvey LDD (1986) Effect of ocean mixing on the transient climate response to a $\mathrm{CO}_{2}$ increase analysis of recent model results. J Geophys Res, Atmos 91(2):2709-2718

Harvey LDD (1989) Managing Atmospheric $\mathrm{CO}_{2}$. Clim Change 15:343-381

Harvey LDD (1996) Polar boundary layer plumes and bottom water formation: a missing element in ocean general circulation models. J Geophys Res 101(C9):799-808

Harvey LDD (2007a) Dangerous anthropogenic interference, dangerous climatic change, and harmful climatic change: non-trivial distinctions with significant policy implications. Clim Change 82(1-2):1-25

Harvey LDD (2007b) Allowable CO2 concentrations under the United Nations Framework Convention on Climate Change as a function of the climate sensitivity probability distribution function. Environ Res Lett 2:014001

Harvey LDD, Huang Z (2001) A quasi-one-dimensional coupled climate-carbon cycle model 1. Description and behavior of the climate component. J Geophys Res 106 (C10):22339-22353

Harvey LDD, Schneider SH (1985) Transient climate response to external forcing on $10^{0}-10^{4}$ year time scales, Part 1: experiments with globally averaged, coupled atmosphere and ocean energy balance models. J Geophys Res 90(D1):2191-2205

Hegerl GC, Zwiers FW, Braconnot P, Gillett NP, Luo Y, Marengo Orsini JA, Nicholls N, Penner JE, Stott PA (2007) Understanding and attributing climate change. In: Solomon S, Qin D, Manning M, Chen Z, Marquis M, Averyt KB, Tignor M, Miller HL (eds) Climate change 2007: the physical science basis. Contribution of Working Group I to the Fourth Assessment Report of the Intergovernmental Panel on Climate Change. Cambridge University Press, Cambridge

Hoffert MI, Callegari AJ, Hsieh CT (1980) The role of deep sea heat storage in the secular response to climatic forcing. J Geophys Res 85(C11):6667-6679

Hooss G, Voss R, Hasselmann K, Maier-Reimer E, Joos F (2001) A nonlinear impulse response model of the coupled carbon cycle-climate system (NICCS). Clim Dyn 18(3-4):189-202

IIASA (2009) International Institute for Applied System Analysis (IIASA) GGI scenario database version 2.0. Available online at: http://www.iiasa.ac.at/Research/GGI/DB/

Jarvis A, Li S (2010) The contribution of timescales to the temperature response of climate models. Clim Dyn. doi:10.1007/s00382-010-0753-y

Johansson DJA, Persson UM, Azar C (2006) The cost of using global warming potentials: analysing the trade-off between $\mathrm{CO}_{2}, \mathrm{CH}_{4}$, and $\mathrm{N}_{2} \mathrm{O}$. Clim Change 77:291-309

Johansson DJA, Persson UM, Azar C (2008) Uncertainty and learning: implications for the trade-off between short-lived and long-lived greenhouse gases. Clim Change 88:293-308

Joshi MM, Gregory JM, Webb MJ, Sexton DMH, Johns TC (2008) Mechanisms for the land/sea warming contrast exhibited by simulations of climate change. Clim Dyn 30(5):455-465

Joos F, Bruno M, Fink R, Siegenthaler U, Stocker TF, Le Quéré C, Sarmiento JL (1996) An efficient and accurate representation of complex oceanic and biospheric models of anthropogenic carbon uptake. Tellus B 48(3):397-417

Knutti R, Hegerl GC (2008) The equilibrium sensitivity of the Earth's temperature to radiation changes. Nat Geosci 1:735-743

Lenton TM, Held H, Kriegler E, Hall JW, Lucht W, Rahmstorf S, Schellnhuber HJ (2008) Tipping elements in the Earth's climate system. PNAS 105(6):1786-1793

Levitus S (1982) Climatological atlas of the world oceans. NOAA Professional Paper 13. US Government Printing Office, Washington, DC 
Li S, Jarvis A (2009) Long run surface temperature dynamics of an A-OGCM: the HadCM3 $4 \times \mathrm{CO}_{2}$ forcing experiment revisited. Clim Dynam 33(6):817-825

Lowe JA, Huntingford C, Raper SCB, Jones CD, Liddicoat SK, Gohar LK (2009) How difficult is it to recover from dangerous levels of global warming? Environ Res Lett 4:014012

Manne AS, Richels RG (2001) An alternative approach to establishing trade-offs among greenhouse gases. Nature 410(6829):675-677

Matthews $\mathrm{HD}$ (2006) Emissions targets for $\mathrm{CO}_{2}$ stabilization as modified by carbon cycle feedbacks. Tellus B 58:591-602

Matthews HD, Caldeira K (2008) Stabilizing climate requires near-zero emissions. Geophys Res Lett 35:L04705

Meehl GA, Washington WM, Collins WD, Arblaster JM, Hu A, Buja LE, Strand WG, Teng H (2005) How much more global warming and sea level rise? Science 307(5716):1769-1772

Meehl GA, Stocker TF, Collins WD, Friedlingstein P, Gaye AT, Gregory JM, Kitoh A, Knutti R, Murphy JM, Noda A, Raper SCB, Watterson IG, Weaver AJ, Zhao Z-C (2007) Global climate projections. In: Solomon S, Qin D, Manning M, Chen Z, Marquis M, Averyt KB, Tignor M, Miller HL (eds) Climate change 2007: the physical science basis. Contribution of Working Group I to the fourth assessment report of the Intergovernmental Panel on Climate Change. Cambridge University Press, Cambridge

Meinshausen $\mathrm{M}$ (2006) What does a $2^{\circ} \mathrm{C}$ target mean for greenhouse gas concentrations? - A brief analysis based on multi-gas emission pathways and several climate sensitivity uncertainty estimates. In: Schellnhuber JS, Cramer W, Nakicenovic N, Wigley TML, Yohe G (eds) Avoiding dangerous climate change. Cambridge University Press, Cambridge

Meinshausen M, Raper SCB, Wigley TML (2008) Emulating IPCC AR4 atmosphere-ocean and carbon cycle models for projecting global-mean, hemispheric and land/ocean temperatures: MAGICC 6.0. Atmos Chem Phys Discuss 8:6153-6272

Meinshausen M, Meinshausen N, Hare W, Raper SCB, Frieler K, Knutti R, Frame DJ, Allen MR (2009) Greenhouse-gas emission targets for limiting global warming to $2^{\circ} \mathrm{C}$. Nature $458: 1158-$ 1162

Munk WH (1966) Abyssal recipes. Deep-Sea Res 13:707-730

Munk WH, Wunsch C (1998) Abyssal recipes II: energetic of tidal and wind mixing. Deep-Sea Res I 45:1977-2010

NASA Goddard Institure for Space Studies (GISS) (2009a) Forcings in GISS climate model. Available online at http://data.giss.nasa.gov/modelforce/

NASA Goddard Institure for Space Studies (GISS) (2009b) GISS surface temperature analysis. Available online at http://data.giss.nasa.gov/gistemp/graphs/. Accessed on 01 April 2009

Nordhaus WD (2008) A question of balance: economic modeling of global warming. Yale University Press, New Haven

O'Neill B, Oppenheimer M (2002) Dangerous Climate Impacts and the Kyoto Protocol. Science 296(5575):1971-1972

O'Neill BC, Oppenheimer M (2004) Climate change impacts are sensitive to the concentration stabilization path. PNAS 101(47):16411-16416

Oppenheimer M, Petsonk A (2005) Article 2 of thee UNFCCC: historical origins, recent interpretations. Clim Change 73:195-226

Plattner GK, Knutti T, Joos F, Stocker TF, von Bloh W, Brovkin V, Cameron D, Driesschaert E, Dutkiewicz S, Edwards NR, Fichefet T, Hargreaves JC, Jones CD, Loutre MF, Matthews HD, Mouchet A, Müller SA, Nawrath S, Price A, Sokolov A, Strassmann KM, Weaver AJ (2008) Long-term climate commitments projected with climate-carbon cycle models. J Climate 21:27212751

Prather M, Ehhalt D, Dentener F, Derwent R, Dlugokencky E, Holland E, Isaksen I, Katima J, Kirchhoff V, Matson P, Midgley P, Wang M (2001) Atmospheric chemistry and greenhouse gases. Houghton JT et al (eds) Climate change 2001: the scientific basis. Cambridge University Press, Cambridge

Ramaswamy V, Boucher O, Haigh J, Hauglustaine D, Haywood J, Myhre G, Nakajima T, Shi GY, Solomon S (2001) Radiative forcing of climate change. In: Houghton JT et al (eds) Climate change 2001: the scientific basis. Cambridge University Press, Cambridge

Randall DA, Wood RA, Bony S, Colman R, Fichefet T, Fyfe J, Kattsov V, Pitman A, Shukla J, Srinivasan J, Stouffer RJ, Sumi A, Taylor KE (2007) Cilmate models and their evaluation. In: Solomon S, Qin D, Manning M, Chen Z, Marquis M, Averyt KB, Tignor M, Miller HL (eds) Climate change 2007: the physical science basis. Contribution of Working Group I to the fourth 
assessment report of the Intergovernmental Panel on Climate Change. Cambridge University Press, Cambridge

Raper SCB, Gregory JM, Osborn TJ (2001) Use of an upwelling-diffusion energy balance climate model to simulate and diagnose A/OGCM results. Clim Dyn 17:601-613

Riahi K, Grubler A, Nakicenovic N (2006) Scenarios of long-term socio-economic and environmental development under climate stabilization. Technol Forecast Soc Change 74(7):887-935

Roe GH, Baker MB (2007) Why is climate sensitivity so unpredictable? Science 318(5850):629-632

Schlesinger ME, Jiang X (1990) Simple model representation of atmosphere-ocean GCMs and estimation of the time scale of $\mathrm{CO}_{2}$-induced climate change. J Climate 3:1297-1315

Schneider SH, Mastrandrea MD (2005) Probabilistic assessment of "dangerous" climate change and emissions pathways. PNAS 102(44):15728-15735

Shine KP, Fuglestvedt JS, Hailemariam K, Stuber N (2005) Alternatives to the global warming potential for comparing climate impacts of emissions of greenhouse gases. Clim Change 68(3):281-302

Smith JB, Schneider SH, Oppenheimer M, Yohe GW, Hare W, Mastrandrea MD, Patwardhan A, Burton I, Corfee-Morlot J, Magadza CHD, Füssel HM, Pittock AB, Rahman A, Suarez A, van Ypersele J-P (2009) Assessing dangerous climate change through an update of the Intergovernmental Panel on Climate Change (IPCC) "reasons for concern". PNAS 106(11):4133-4137

Stern NH (2006) Stern review: the economics of climate change. Cambridge University Press, Cambridge

Stouffer RJ (2004) Time scales of climate response. J Climate 17:209-217

Tanaka K (2008) Inverse estimation for the simple Earth system model ACC2 and its applications. $\mathrm{PhD}$ thesis, International Max Planck Research School on Earth System Modelling, Hamburg, Germany. Available online at http://www.sub.uni-hamburg.de/opus/volltexte/2008/3654/

Thorn MS, Harte J (2006) Missing feedbacks, asymmetric uncertainties, and the underestimation of future warming. Geophys Res Lett 33:L10703

USEPA (2006) Global mitigation of non-CO2 greenhouse gases. US Environmental Protection Agency, Office of Atmospheric Programs (6207J), Washington DC

Velders GJM, Fahey DW, Daniel JS, McFarland M, Anderson SO (2009) The large contribution of projected HFC emissions to future climate forcing. PNAS 106(27):10949-10954

Whitworth T III, Warren BA, Nowlin WD Jr, Rutz SB, Pillsbury RD, Moore MI (1999) On the deep western-boundary current in the Southwest Pacific Basin. Prog Oceanogr 43:1-54

Wigley TML (1991) A simple inverse carbon cycle model a simple inverse carbon cycle model. Glob Biogeochem Cycles 5(4):373-382

Wigley TML (2004) Modeling climate change under no-policy and policy emissions pathways. In: Gramme $\mathrm{T}$ (ed) The benefits of climate change policies: analytical and framework issues. OECD, Paris, pp 221-248

Wigley TML (2005) The climate change commitment. Science 307(5716):1766-1769

Wigley TML, Schlesinger ME (1985) Analytical solution for the effect of increasing $\mathrm{CO}_{2}$ on global mean temperature. Nature 315:649-652

Wigley TML, Raper SCB (2001) Interpretation of high projections for global-mean warming. Science 293(5529):451-454

Wigley TML, Smith SJ, Prather MJ (2002) Radiative forcing due to reactive gas emissions. J Climate 15:2690-2696 